\title{
Mapping Soil Moisture with the OPtical TRApezoid Model (OPTRAM) using Long-Term MODIS Observations
}

Ebrahim Babaeian ${ }^{1, *}$, Morteza Sadeghi², Trenton E. Franz ${ }^{3}$, Scott Jones ${ }^{2}$, Markus Tuller ${ }^{1}$

${ }^{1}$ Dept. Soil, Water and Environmental Science, The University of Arizona, Tucson, Arizona

${ }^{2}$ Dept. Plants, Soils and Climate, Utah State University, Logan, Utah

${ }^{3}$ School of Natural Resources, University of Nebraska-Lincoln, Lincoln, Nebraska

${ }^{*}$ Corresponding Author at 1177 E. $4^{\text {th }}$ Street, Tucson, Arizona 85721, USA

E-mail address: ebabaeian@email.arizona.edu (E. Babaeian), morteza.sadeghi@usu.edu (M. Sadeghi), tfranz2@unl.edu (T.E. Franz), scott.jones@usu.edu (S.B. Jones), mtuller@cals.arizona.edu (M. Tuller)

\begin{abstract}
The OPtical TRApezoid Model (OPTRAM) has recently been proposed for estimation of soil moisture using only optical remote sensing data. The model relies on a physical linear relationship between the soil moisture content and shortwave infrared transformed reflectance (STR) and can be parameterized universally (i.e., a single calibration for a given area) based on the pixel distribution within the STR-Normalized Difference Vegetation Index (NDVI) trapezoidal space. The main motivation for this study is to evaluate how the universal parameterization of OPTRAM works for long periods of time (e.g., several decades). This is especially relevant with regard to uncovering the soil moisture and agricultural drought history in response to climate
\end{abstract}


change in different regions. In this study, MODIS satellite observations from 2001 to 2017 were acquired and used for the analysis. Cosmic-ray neutron (CRN) soil moisture data, collected with the COsmic-ray Soil Moisture Observing System (COSMOS) at five different sites in the U.S. covering diverse climates, soil types, and land covers, were applied for evaluation of the MODISOPTRAM-based soil moisture estimates. The OPTRAM soil moisture estimates were further compared to the Soil Moisture Active and Passive (SMAP) (L-band), the Soil Moisture Ocean Salinity (SMOS) (L-band), and the Advanced AScatterometer (ASCAT) (C-band) soil moisture retrievals. OPTRAM soil moisture data were also analyzed for potential monitoring of agricultural drought through comparison of the OPTRAM-based Soil Water Deficit Index (OPTRAM-SWDI) with the widely-applied Crop Moisture Index (CMI). Evaluation results indicate that OPTRAMbased soil moisture estimates provide overall unbiased RMSE and $R$ between 0.050 to $0.085 \mathrm{~cm}^{3}$ $\mathrm{cm}^{-3}$ and 0.10 to 0.70 , respectively, for all investigated sites. The performance of OPTRAM is comparable with the ASCAT retrievals, but slighly less accurate than SMAP and SMOS. OPTRAM and the three microvave satellites captured CRN soil moisture temporal dynamics very well for all five investigated sites. A close agreement was observed between the OPTRAM-SWDI and CMI drought indices for most selected sites. In conclusion, OPTRAM can estimate temporal soil moisture dynamics with reasonable accuracy for a range of climatic conditions (semi-arid to humid), soil types, and land covers, and can potentially be applied for agricultural drought monitoring.

Keywords: Soil moisture mapping, The optical trapezoid model OPTRAM, Drought monitoring, Cosmic-ray neutron soil moisture, MODIS, SMAP, SMOS, ASCAT 


\section{Introduction}

Soil moisture is a highly dynamic state variable that controls fundamental hydrological processes such as evaporation, infiltration, and runoff. It is also critical for management and allocation of water resources, prediction and monitoring of drought, agricultural production, mitigation of natural disasters and monitoring of ecosystem response to climate change (Robinson et al., 2008; Vereecken et al., 2014; Babaeian et al., 2016).

Remote sensing techniques provide powerful means for characterizing and monitoring the high spatiotemporal variability of soil moisture. During the past decade, several satellites with various spatiotemporal resolutions have been launched for monitoring near surface $(0-5 \mathrm{~cm})$ soil moisture, including the European Soil Moisture and Ocean Salinity (SMOS) Satellite, launched in 2009 (Kerr et al., 2001), the Advanced Microwave Scanning Radiometer 2 (AMSR-2) on the Global Change Observation Mission-Water (GCOM-W1) Satellite, launched in 2012, the Advanced Scatterometer (ASCAT) launched in 2006 on the EUMETSAT MetOp-A and MetOpB satellites, the ESA Sentinel-1 Satellite launched in 2014 (Bartalis et al., 2007), and NASA's Soil Moisture Active-Passive (SMAP) Satellite, launched in 2015 (Entekhabi et al., 2010). These microwave satellites yield the most accurate measurements of soil moisture (Mattikalli et al., 1998) because of the high dielectric permittivity of soil water within the microwave domain (Hallikainen et al., 1985) and the greater penetration of microwaves through vegetation canopy and underlying soil (Escorihuela et al., 2010; Chapin et al., 2012; Tabatabaeenejad et al., 2015).

Passive microwave satellites commonly provide high temporal resolution observations (e.g., daily), but suffer from low spatial resolution. In this context, optical and thermal remote sensing observations provide higher spatial resolution information and thus are often used to enhance the passive microwave soil moisture maps through data fusion and downscaling 
approaches (e.g., Piles et al., 2014; Merlin et al., 2012). Hence, development of robust optical and thermal methods, in concert with microwave techniques, can improve remote sensing of soil moisture.

The trapezoid (or triangle) model is a widely-applied approach to remote sensing of soil moisture based on thermal (land surface temperature, LST) and optical data (Carlson et al. 1994; Gillies and Carlson, 1995; Owen et al., 1998; Rahimzade-Bajgiran et al., 2013; Shafian and Mass, 2015; Sun, 2016). Despite the triangle model's obvious success discussed in Sadeghi et al. (2017), it suffers from two inherent limitations. The first is the requirement of concurrent optical and thermal data, which renders the model inapplicable to satellites that do not provide thermal data, e.g. ESA Sentinel-2. The second limitation is that the land surface temperature is not only affected by soil moisture content but also by ambient atmospheric conditions (e.g., wind speed, air temperature, and air humidity). Hence, the conventional trapezoid model needs time consuming and computationally demanding individual parameterization (calibration) for each individual observation date. To overcome these two limitations, Sadeghi et al. (2017) proposed the physically-based OPtical TRApezoid Model (OPTRAM) for estimation of surface soil moisture. The OPTRAM trapezoid is formed by distribution of the normalized difference vegetation index (NDVI) as a measure of vegetation fraction versus shortwave-infrared (SWIR) transformed reflectance to obtain soil moisture content. This concept was introduced by Sadeghi et al. (2015). The OPTRAM does not require a thermal band, hence, it is applicable to satellites providing optical bands only (this resolves the first limitation of the conventional trapezoid model). Because SWIR reflectance does not significantly change with ambient atmospheric conditions, OPTRAM can be universally parameterized for a given location (this resolves the second limitation of the conventional trapezoid model). 
OPTRAM has been initially evaluated in Sadeghi et al. (2017) based on ESA Sentinel-2 and NASA Landsat-8 satellite observations for mapping of soil moisture in the Walnut Gulch and Little Washita watersheds in Arizona and Oklahoma, respectively. Because Sentinel-2 was only recently launched (i.e., in summer 2015), the time period covered in the Sadeghi et al. (2017) study was limited to a few months in 2015 and 2016. Hence, the main motivation for this current study has been to evaluate how the universal parameterization of OPTRAM (i.e., a single calibration for a given area) works for long periods of time (e.g., several decades). This is especially important with regard to expanding our ability to uncover the soil moisture history in response to climate changes in different regions.

Long-term soil moisture data provide a useful measure for monitoring agricultural drought (Chakrabarti et al., 2014), which is defined based on soil water deficit and its effects on crop production. Recently, several studies have shown the potential of remotely sensed soil moisture data for agricultural drought monitoring (Chakrabarti et al., 2014; Martinez-Fernandez et al., 2016; Carrao et al., 2016; Mishra et al., 2017; Liu et al., 2017). Several soil moisture-based drought indices have also been introduced for agricultural drought monitoring including the Soil Moisture Index (SMI) (Sridhar et al., 2008), Soil Water Deficit (SWD) (Torres-Ruiz et al., 2013), Plant Available Water (PAW) (McPherson et al., 2007), Drought Severity Index (DSI) (Cammalleri and Vogt, 2016), Soil Moisture Drought Index (SMDI) (Sohrabi et al., 2015), and Soil Water Deficit Index (SWDI) (Martinez-Fernandez et al., 2015). Among these drought indices, SWDI is a simple agricultural drought index that is computed based on plant water availability, which is assumed to not change over long time periods. The SWDI has been recently used in conjunction with remotely sensed soil moisture estimates from SMAP and SMOS for monitoring agricultural drought (Martinez-Fernandez et al., 2016; Mishra et al., 2017). The application of microwave-based soil 
moisture retrievals (e.g., SMAP, SMOS, Sentinel-1) for long-term monitoring of agricultural drought is limited due to the lack of soil moisture data for long periods of time. The optical satellites such as Landsat and MODIS, launched many years before SMAP, SMOS, and Sentinel1, provide a unique opportunity for such analysis in order to fill this critical observational gap.

The specific objectives of this study were to: (i) evaluate the universally-parameterized OPTRAM for estimation of soil moisture with long-term MODIS data for four typical watersheds in the United States, which exhibit diverse climates, soil types, and land covers, (ii) compare the accuracy of OPTRAM soil moisture estimates with retrievals from microwave satellites (i.e., SMAP, SMOS, ASCAT), and (iii) explore the feasibility of applying long-term OPTRAM soil moisture data for agricultural drought monitoring.

\section{Background: The Optical Trapezoid Model (OPTRAM)}

Sadeghi et al. (2017) proposed a physically-based trapezoidal space termed the "optical trapezoid model” (OPTRAM) for remote sensing of soil moisture based on optical data only. The concept is based on the pixel distribution within the STR-NDVI space, where STR is the SWIR transformed reflectance and $N D V I$ is the normalized difference vegetation index, thereby replacing LST in the conventional trapezoid model. Considering a linear relationship between soil saturation degree, $W$ (0 for fully dry and 1 for saturated soil) and STR (Sadeghi et al., 2015) results in:

$$
W=\frac{S T R-S T R_{d}}{S T R_{w}-S T R_{d}}
$$

where:

$$
S T R=\frac{(1-R)^{2}}{2 R}
$$


where $S T R_{d}$ and $S T R_{w}$ are $S T R$ at dry (e.g., $\theta \sim 0 \mathrm{~cm}^{3} \mathrm{~cm}^{-3}$, where $\theta$ is volumetric moisture content) and wet (e.g., $\theta=\theta_{s} \mathrm{~cm}^{3} \mathrm{~cm}^{-3}$, where $\theta_{s}$ is saturated moisture content) states, respectively, and $R$ is surface reflectance for the SWIR (2130 nm, MODIS band 7) electromagnetic domain. Assuming empirical linear relationships of $S T R_{d}$ and $S T R_{w}$ with vegetation fraction, the dry and wet edges of the optical trapezoid are defined as follows (see Fig. 1):

$S T R_{d}=i_{d}+S_{d} N D V I$

$S T R_{W}=i_{W}+s_{W} N D V I$

where $i_{d}$ and $s_{d}$ are intercept and slope of the dry edge and $i_{w}$ and $s_{w}$ are intercept and slope of the wet edge.

Based on Eqs. (1), (3) and (4), soil moisture within a given satellite image pixel can be estimated from its STR and NDVI values:

$W=\frac{i_{d}+s_{d} N D V I-S T R}{i_{d}-i_{w}+\left(s_{d}-s_{w}\right) N D V I}$

where the saturation degree $W$ can be expressed as $\theta\left(\mathrm{cm}^{3} \mathrm{~cm}^{-3}\right)$ multiplied with the soil porosity (assumed equal to $\theta_{s}$ ).

As discussed in Sadeghi et al. (2017), unlike the conventional trapezoidal space (LST vs. $N D V I$ ) that varies over time due to variation of the ambient atmospheric parameters, the STR-NDVI space is nearly time-invariant because surface reflectance is only dependent on surface properties and not on the ambient atmospheric parameters. Therefore, we hypothesize that a universal parameterization of Eq. (5) is possible with prolonged time series of satellite observations for any specific location. 


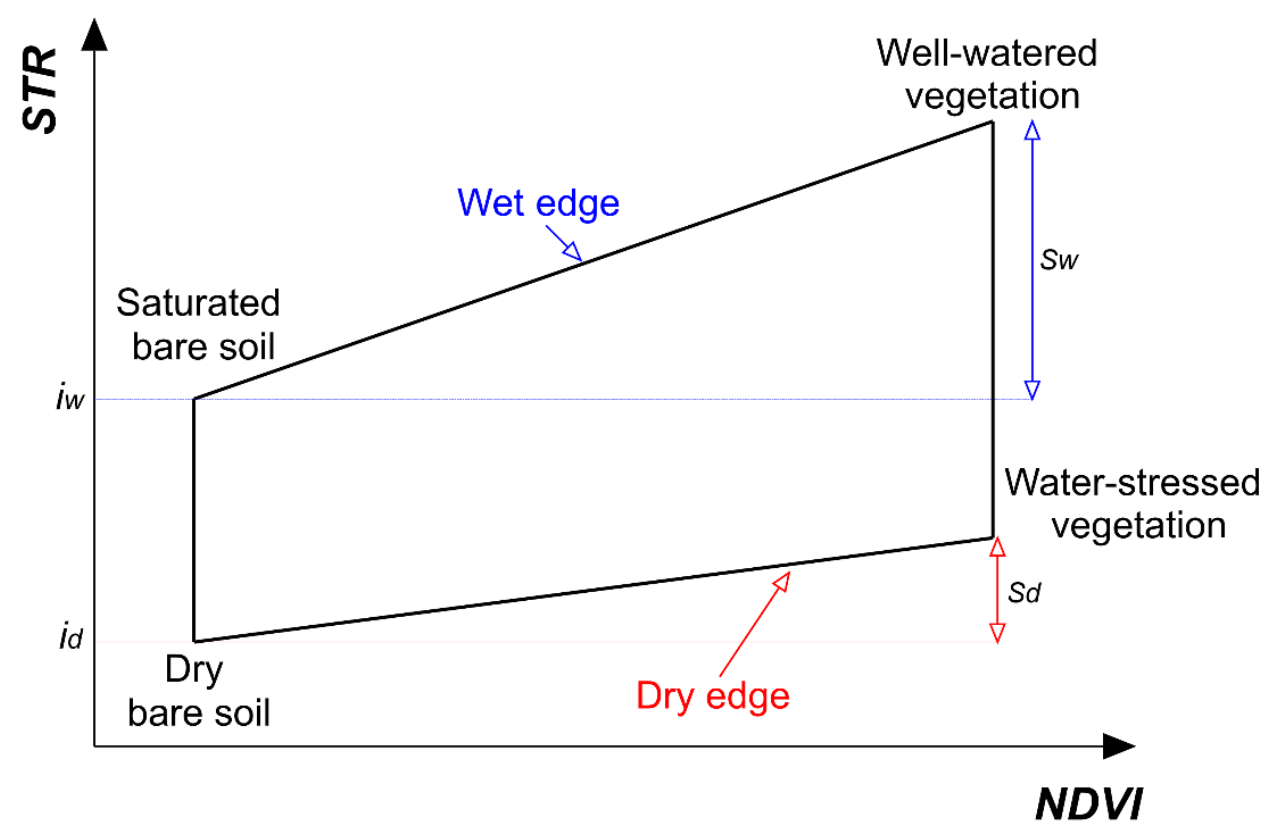

Fig. 1. The optical trapezoid model (OPTRAM) relating STR [Eq. (2)] and NDVI.

\section{Materials and Methods}

\subsection{Study Areas}

The OPTRAM was evaluated for four watersheds in the United States with diverse climates, soil types and land covers, where existing cosmic-ray neutron (CRN) soil moisture observations were used as reference for soil moisture data (Fig. 2). Characteristics of the CRN sites within the four watersheds are summarized in Table 2. A brief introduction of these watersheds follows. 


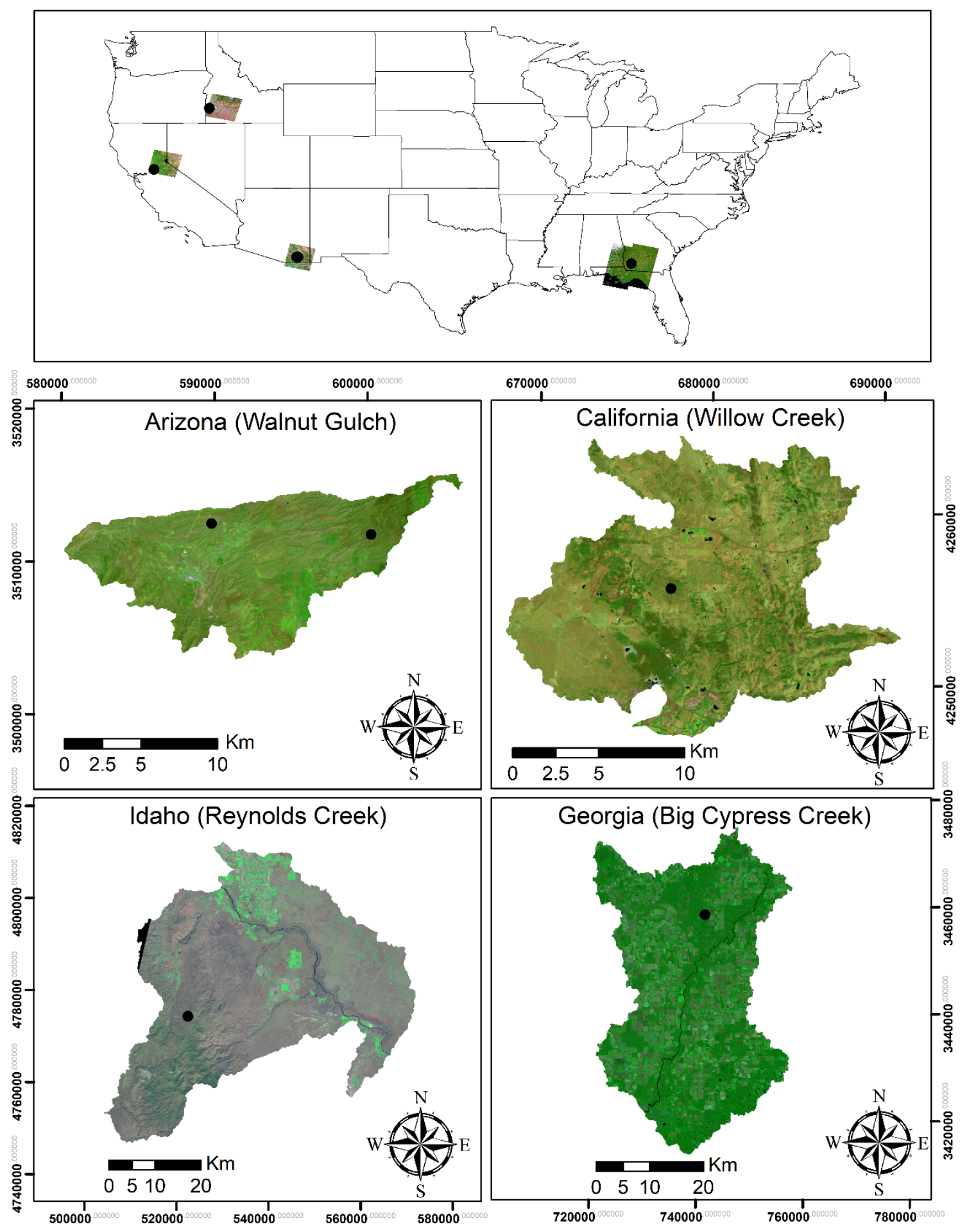

Fig. 2. Geographical location of the selected watersheds for evaluation of OPTRAM. Landsat 8 shortwave infrared, near infrared, and green bands (September 2018) were used to create false-color composite images (as 7-5-3 bands) in which vegetation-covered lands appears deep green. The locations of the cosmic-ray neutron soil moisture sites are marked with full circles.

Table 1. Characteristics of the CRN sites within the four selected watersheds. 


\begin{tabular}{|c|c|c|c|c|c|c|}
\hline Watershed's name & CRN site & $\begin{array}{l}\text { Temporal } \\
\text { coverage }\end{array}$ & Latitude & Longitude & $\begin{array}{c}\text { Lattice } \\
\text { water (\%) }\end{array}$ & $\begin{array}{l}\text { Soil organic } \\
\text { carbon (\%) }\end{array}$ \\
\hline \multirow[t]{2}{*}{$\begin{array}{l}\text { Walnut Gulch } \\
\text { (WGW) }\end{array}$} & $\begin{array}{l}\text { Lucky } \\
\text { Hills }\end{array}$ & $\begin{array}{l}\text { 13-Mar-2012 to } \\
\text { 31-Jan-2016 }\end{array}$ & 31.744 & -110.052 & 1.50 & 3.65 \\
\hline & Kendal & $\begin{array}{l}\text { 02-Jun-2010 to } \\
\text { 7-Jan-2017 }\end{array}$ & 31.737 & -109.942 & 2.40 & 0.80 \\
\hline $\begin{array}{l}\text { Willow Creek } \\
\text { (WCW) }\end{array}$ & $\begin{array}{l}\text { Tonzi } \\
\text { Ranch }\end{array}$ & $\begin{array}{l}\text { 10-May-2011 to } \\
\text { 31-May-2017 }\end{array}$ & 38.432 & -120.966 & 6.05 & 0.55 \\
\hline $\begin{array}{l}\text { Reynolds Creek } \\
\text { (RCW) }\end{array}$ & $\begin{array}{l}\text { Reynolds } \\
\text { Creek }\end{array}$ & $\begin{array}{l}\text { 10-Aug-2011 to } \\
\text { 31-May-2017 }\end{array}$ & 43.121 & -116.723 & 5.70 & 2.62 \\
\hline $\begin{array}{l}\text { Big Cypress Creek } \\
\text { (BCCW) }\end{array}$ & JERC & $\begin{array}{l}\text { 19-Sep-2011 to } \\
\text { 16-May-2017 }\end{array}$ & 31.236 & -84.462 & 1.08 & 0.66 \\
\hline
\end{tabular}

\subsubsection{Walnut Gulch, Arizona}

The Walnut Gulch Watershed (WGW), located in southeastern Arizona (AZ), with an area of $148 \mathrm{~km}^{2}$ is one of the most intensively instrumented semi-arid rangeland watersheds in the world. It was developed as a research watershed for hydrologic and atmospheric sciences by the United States Department of Agriculture (USDA) in 1953. The watershed has been frequently used as a core validation site for aircraft- and satellite-based remote sensing of soil moisture. The WGW includes two CRN sites: 'Lucky Hills' and 'Kendal'. They are dominantly covered with desert shrubs (two thirds) and desert grasses (one third). The soils are mostly sandy loam and gravelly loam with little organic matter content. The climate is semi-arid with an average annual temperature $17.7{ }^{\circ} \mathrm{C}$ and an annual average precipitation of $350 \mathrm{~mm}$; about two-thirds commonly falls during the summer monsoon season (July to September). The potential evapotranspiration is approximately ten times the annual precipitation. The topography is gently rolling hills incised by steep drainage channels (Renard et al., 1993; Keefer et al., 2008).

\subsubsection{Willow Creek, California}

The Willow Creek Watershed (WCW) with an area of $58 \mathrm{~km}^{2}$ is located East of Sacramento, California (CA). The watershed encompasses the ‘Tonzi Ranch’ CRN site that has 
been established in a fairly flat area and is covered with oak-grass savanna. Tonzi Ranch is one of the SMAP validation sites. Sandy clay loam with low organic matter content is the dominant soil texture. The land surface is covered with mixed forests, grasslands and shrublands. The typical land forms consist of plains, shallow valleys, and hills. The elevation ranges from 50 to $450 \mathrm{~m}$ above sea level. The climate is Mediterranean with an average annual temperature of $16^{\circ} \mathrm{C}$ and an average annual precipitation of $560 \mathrm{~mm}$ mostly falling between November and March.

\subsubsection{Reynolds Creek, Idaho}

The USDA Reynolds Creek Experimental Watershed (RCW), located in Southwestern Idaho (ID), is a key watershed that has been established to support research addressing issues of water quantity and quality, seasonal snow, and rangeland hydrology of the interior Pacific northwest. The RCW is equipped with one CRN station and very well instrumented with neutron access tubes, weirs, fiber optic temperature cables, and snow survey stakes. It is one of the core validation sites for remote sensing of soil moisture based on SMAP data. The climate in the region varies from arid to temperate with an average annual precipitation ranging from less than $250 \mathrm{~mm}$ in the North part of the watershed to more than $1150 \mathrm{~mm}$ at the highest elevation in the Southwest. Annual snow varies from approximately $20 \%$ of the annual precipitation in the lower elevations to more than $70 \%$ at the higher elevations. The average annual temperature ranges from $7.2^{\circ} \mathrm{C}$ in low elevations to $3.9^{\circ} \mathrm{C}$ in high elevations. The land use is dominated by rangland that is covered with mixed sagebrush shrubs and grasses. The topography is fairly steep. The Western part of the watershed is sparsly vegetated with very rocky soils, while the Eastern part exhibits silty soils with dense vegetation cover. 


\subsubsection{Big Cypress Creek, Georgia}

The Big Cypress Creek Watershed (BCCW) is located in the Southwest of Georgia (GA). It covers the northern part of the Lower Flint River and the Lower Big Slough watersheds and the western part of the Horseshoe Bend-flint River watershed. The BCCW encompasses the 'Jones Ecological Research Center' (JERC) CRN site. The climate in the region is humid subtropical. The average annual precipitation ranges from $1140 \mathrm{~mm}$ in the eastern part to $1400 \mathrm{~mm}$ in the southern part of the watershed. The average annual temperature ranges from $15.5^{\circ} \mathrm{C}$ in the North to $21^{\circ} \mathrm{C}$ in the South (USGS, 1986). The region in entirely flat with mixed land covers including evergreen forests with grass understory and agricultural lands. The predominant soil type is very well drained deep sand with deep water table.

\subsection{Reference Soil Moisture Data}

As mentioned earlier, CRN observations were used as the reference soil moisture data. The CRN method (Zreda et al., 2008) provides a unique opportunity to non-invasively measure effective soil moisture within the topsoil and to fill the scale gap between point-scale in situ data and large-scale remote sensing observations. Given a footprint area close to that of MODIS (detailed below), the CRN data provide an excellent means for evaluation of OPTRAM soil moisture estimates from MODIS observations.

Based on neutron transport simulations, Zreda et al. (2008) found that $86 \%$ of the neutron signal occurs within a 335-m radius at sea level, which is nearly independent of the soil moisture level. They also found that the vertical extent of the neutron signal depends on soil moisture content and ranges from about $15 \mathrm{~cm}$ in saturated soils to about $70 \mathrm{~cm}$ in very dry soils. Recent particle transport simulations show a similar footprint area in the order several hundred meters 
albeit with more spatial sensitivity of soil moisture within the footprint (Desilets and Zreda, 2013; Kohli et al., 2015). The exact CRN footprint and sensitivity are still an active area of research. The CRN data have been recently used for validation of spaceborne surface soil moisture products such as SMAP, SMOS, and ASCAT for COSMOS sites in the United States, Australia, Europe and Africa (Montzka et al., 2017; Akbar and Moghaddam, 2015; Fascetti et al., 2016; van der Schalie et al., 2016). Currently, there are approximately 194 permanent CRN stations worldwide (Andreasen et al. 2017), including 73 COSMOS stations in the U.S. (Zreda et al., 2012), 20 TERENO stations in Germany (Baatz et al., 2015), 13 CosmOz stations in Australia (Hawdon et al., 2014), and 32 COSMOS-UK stations in the United Kingdom (Evans et al., 2016) all of which provide excellent data for remotely sensed soil moisture validation and evaluation experiments.

The CRN detects the ambient low-energy neutron density in the air. The low-energy neutrons are highly sensitive to the mass of hydrogen and thus soil water near the ground surface (Zreda et al., 2012; Avery et al., 2016). A calibration function that relates the change in low-energy neutrons to the change in hydrogen content is commonly developed for estimation of soil moisture. The CRN is also affected by other hydrogen sources (e.g., atmospheric water vapor, soil organic matter, and mineral lattice water), and thus may provide soil moisture values exceeding the soil porosity, especially in very humid regions (Franz et al., 2012; Bogena et al., 2013; Baatz et al. 2015). In such cases, the influence of additional sources of hydrogen should be accounted for in the CRN soil moisture calibration. For this study, we corrected the CRN soil moisture data based on the method proposed in Franz et al. (2013) and Bogena et al. (2013) as follows:

$$
\theta_{v}=\rho_{b}\left[\frac{0.0808}{\left(\frac{N_{\text {pih }}}{N_{0}}\right)-0.372}-0.115-\theta_{l w}-\theta_{\text {soceq }}\right]
$$


where $\theta_{v}$ is the volumetric moisture content $\left(\mathrm{cm}^{3} \mathrm{~cm}^{-3}\right), \theta_{l w}$ is lattice water content $\left(\mathrm{g} \mathrm{g}^{-1}\right), \theta_{\text {soceq }}$ is soil organic carbon water content equivalent $\left(\mathrm{g} \mathrm{g}^{-1}\right), N_{p i h}$ is the corrected neutron intensity (moderated neutron counts per time interval, $\mathrm{cph}$ ), $N_{0}$ is a specific calibrated parameter that represents the count rate over dry soils (cph), $\rho_{b}$ is the dry soil bulk density $\left(\mathrm{g} \mathrm{cm}^{-3}\right)$. The $\theta_{l w}$ and $\theta_{\text {soceq }}$ data were obtained from calibration datasets provided on the COSMOS data portal (http://cosmos.hwr.arizona.edu). More details about CRN calibration and accounting for various hydrogen sources are provided in Franz et al. (2012), Rosolem et al. (2013), Bogena et al. (2013), and Lv et al. (2014).

The precipitation data were extracted from the closest SNOwpack TELemetry (SNOTEL) and Soil Climate Analysis Network (SCAN) sites.

\subsection{Satellite Data}

\subsubsection{MODIS}

The Moderate Resolution Imaging Spectroradiometer (MODIS) is a key instrument on board of NASA's Terra (EOS AM-1) and Aqua (EOS PM-1) satellites that plays an important role in studying land surface properties and processes and development of models to predict global change. Terra and Aqua MODIS satellites capture the entire Earth surface every 1 to 2 days and acquire data in 36 individual spectral bands (400-14400 nm) at resolutions of $250 \mathrm{~m}$ (bands 1-2), 500 m (bands 3-7), and 1000 m (bands 8-36). In this study, long-term cloud-free MODIS land surface reflectance images (Terra MOD09A1 version 6) from 2001 to 2017 were acquired and analyzed. This product provides spectral reflectance at bands 1-7 with $500 \mathrm{~m}$ spatial resolution and 8-day temporal resolution as a gridded level-3 product in the Sinusoidal projection. Each MOD09A1 pixel contains the best possible observation during an 8-day period as selected on the 
basis of high observation coverage, low view angle, the absence of clouds and cloud shadows, and aerosols. Reflectance values from bands 1 (Red) and 2 (Near Infrared, NIR) were used to calculate $N D V I=(N I R-R e d) /(N I R+R e d)$ and reflectance from band $7(S W I R, 2130 \mathrm{~nm})$ was used for calculating STR with Eq. (2). The key reason for selecting SWIR range in the STR-NDVI space is based on that the spectral reflectance in wavelengths around $2200 \mathrm{~nm}$ (corresponding to MODIS band 7) has stronger and more linear relationship with soil moisture content than other SWIR wavelengths (e.g., 1240 and $1640 \mathrm{~nm}$ corresponding to bands 5 and 6 MODIS) (Sadeghi et al., 2015). On the other hand, MODIS SWIR band 7 used in Eq. (2) is far from water absorption bands in SWIR region (i.e., $1400 \mathrm{~nm}$ and $1900 \mathrm{~nm}$ ), making the effect of atmosphere water vapor negligible on spectral reflectance data. The images were analyzed and projected into WGS84 geographic coordinates using the HDF-EOS 2.14 tool (http://hdfeos.org/) and MATLAB R2015b (Math Works Inc., Natick, MA) software.

\subsubsection{SMAP}

The L-band Soil Moisture Active and Passive (SMAP) satellite has been designed and launched by NASA with the major aim of measuring and monitoring soil moisture changes (Entekhabi et al., 2010). The SMAP released 7 advanced soil moisture products as levels 2, 3, and 4 that provide surface and root zone soil moisture with spatial resolutions of 3, 9, and $36 \mathrm{~km}$ and temporal resolutions of 3 and 24 hours. In this study, the level-3 product (L3_SM_P, descending 6:00 a.m.), derived from the single channel algorithm V-Pol (SCA-V) and resampled to a global and cylindrical $36 \mathrm{~km}$ resolution with Equal-Area Scalable Earth Grid (EASE-Grid 2.0) global projection, was applied and compared with CRN reference data to further evaluate the MODISbased estimates of soil moisture with OPTRAM. This level-3 product provides a daily composite 
of half-orbit/swath estimates of global surface soil moisture $\left(0-5 \mathrm{~cm}^{3} \mathrm{~cm}^{-3}\right)$ derived from the brightness temperature data measured by the passive microwave radiometer.

\subsubsection{SMOS}

Launched in 2009, the ESA Soil Moisture and Ocean Salinity (SMOS) satellite is the first Earth observation mission dedicated to map and monitor surface soil moisture (Kerr et al., 2001). The SMOS uses the L-band microwave emissions of the biosphere (L-MEB) radiative transfer model (Wigneron et al., 2007) and a dielectric mixing model (Mironov et al., 2009) to retrieve surface soil moisture $\left(0-5 \mathrm{~cm}^{3} \mathrm{~cm}^{-3}\right)$. A new algorithm, referred to as SMOS-IC, based on the LMEB model has recently been developed for improving SMOS soil moisture retrieval (FernandezMoran et al., 2017). The surface soil moisture maps are generated as global products with a $25 \mathrm{~km}$ (EASE-Grid 2.0) grid size. In the current study, the daily level-3 soil moisture product (Version 3.0) was used and compared with the CRN reference data to further evaluate the MODIS-based estimates of soil moisture with OPTRAM. The level-3 product is obtained at 6:00 am local time from the ascending orbit and derives from the level-2 Soil Moisture Processor equivalent of version 6.20 (Kerr et al., 2012).

\subsubsection{ASCAT}

The Advanced Scatterometer (ASCAT) is an active C-band microwave sensor on the METOP-A/B satellite platforms, launched in 2006. The sensor was initially designed for monitoring wind speed and wind direction over the oceans, but it has been widely used for monitoring soil moisture in terms of relative saturation (Wagner et al., 2013). The relative saturation is estimated based on a simple linear change detection retrieval algorithm which is part 
of the Water Retrieval Package (WARP) software (Naeimi et al., 2009). A shortcoming of this algorithm is that it considers a linear relationship between the backscatter coefficient (dB) and surface soil moisture, while assuming that surface roughness and land cover are constant in time. While ASCAT provides accurate estimates of soil moisture for bare and sparsely vegetated soils, retrievals for densely vegetated regions (e.g., tropical forests) are associated with significant errors, since backscatter from soil and vegetation cannot be separated (Wagner et al., 2013). The EUMETSAT has generated several ASCAT surface and root zone soil moisture products with daily global coverage. In the current study, we used the H109 and H110 soil moisture products from 2010 to 2016 , with $12.5 \mathrm{~km}$ spatial sampling. The relative soil saturation was converted to volumetric moisture content via multiplying with the soil porosity found in the Harmonized World Soil Database (HWSD, Nachtergaele et al., 2012). Soil moisture data with noise designation above 20\% were excluded from our analyses, while all remaining data were compared with the CRN reference data (Montzka et al., 2017).

\subsection{Data Analyses}

\subsubsection{OPTRAM Parameterization}

The dry and wet edges of the OPTRAM were determined through parameterization of Eq. (5) based on the pixel distribution within the STR-NDVI space. This space was formed by overlaying all STR and NDVI images collected from 2001 to 2017 period, where an integrated trapezoid was formed for each watershed using several hundred images acquired over each watershed (see Table 2). Overlaying long-term MODIS images makes an integrated STR-NDVI trapezoid that provides a good opportunity for determining effective values of the dry and wet edge parameters across each region. This way may reduce scene- or time-dependency of dry and wet 
edge parameters and provide "effective" parameters that minimize calibration requirements for Eq. (5) to estimate soil moisture. To remove the effect of non-vegetated and non-soil pixels (e.g., water, snow, rock), the $N D V I$ values in the range of zero to 1 were applied.

This approach provides a universal parameterization of Eq. (5) so that the optimized parameters are time-invariant for each region. The dry $\left(i_{d}\right.$ and $\left.s_{d}\right)$ and wet ( $i_{w}$ and $s_{w}$ ) parameters were determined through visual fitting of a straight line to the point clouds within the STR-NDVI space, as suggested by Carlson et al. (2013) and Sadeghi et al. (2017).

The saturation degree $(W)$ was mapped with Eq. (5) for each date and watershed. The estimated $W$ values for pixels containing the CRN sites were converted to volumetric moisture contents by multiplying with the soil porosity values from the HWSD. To quantify the sensitivity of OPTRAM soil moisture to visually fitting the dry and wet edges, a sensitivity analysis was performed based on the original fitted edges within $\pm \% 5, \pm \% 10, \pm \% 15$, and $\pm \% 20$ range. For example, at level $\pm \% 5$ and for each parameter, a random coefficient with 4 replicates (R1 to R4 in Fig. 4) was produced between -5 and 5 . Then these random coefficients for each parameter were exerted to the initial dry and wet edge parameters to produce the new dry and wet edge parameters within each uncertainty level. Using Eq. (5) and for each sensitivity level, soil moisture content was determined based on the new sets of the dry and wet edges parameters and then compared to those from the initial dry and wet edge parameters (see section 3.2). We note that Sadeghi et al. (2017) resampled Landsat-8 and Sentinel-2 images to 120-m pixels to remove effects of oversaturated pixels, while here we employed the original MODIS pixels because oversaturated pixels are unlikely at $500 \mathrm{~m}$ spatial resolution unless they cover surface water bodies. The resultant optical trapezoids for the four investigated watersheds (shown later in Fig. 3) verified this assumption, as the wet edge data were obtained within the expected STR range for saturated/wet land. 


\subsubsection{Rescaling Soil Moisture Data}

Soil moisture data from different sources (e.g., satellite vs. in situ, or varied satellites) typically exhibit consistent temporal evolution, but different mean and standard deviation values. Hence, rescaling data through matching the cumulative probability (CP) or cumulative distribution function (CDF) has been recommended for reducing systematic biases between different soil moisture datasets (Reichle and Koster, 2004; Koster et al., 2009; Brocca et al., 2011; Mishra et al., 2017). The CDF matching removes impacts of time-invariant errors from comparison between estimated and measured soil moisture and provides an objective basis for intercomparisons of anomalies. In this paper, we followed the strategy of Reichle and Koster (2004) and matched the CDF of remotely sensed soil moisture data to the CRN reference data (Crow et al., 2005; Kumar

et al., 2012). Accordingly, we calculated the bias-corrected (rescaled) remotely sensed soil moisture, $\theta_{R S}$, from original remotely sensed soil moisture, $\theta_{R S}^{\prime}$, as follows:

$\theta_{R S}=\mu_{C R N}+\left(\theta_{R S}^{\prime}-\mu_{R S}\right) \frac{\sigma_{C R N}}{\sigma_{R S}}$

where $\mu$ and $\sigma$ represent the mean and standard deviation of soil moisture data, respectively, for a given location for the study period, and subscripts $R S$ and $C R N$ denote the corresponding data sources.

\subsubsection{Performance Metrics}

For each comparison of pairs of remotely sensed and reference (CRN) soil moisture observations, the correlation coefficient $(R)$, the root mean squared error (RMSE), bias, and unbiased RMSE (ubRMSE) were applied as follows: 


$$
\begin{aligned}
& R=\frac{\operatorname{Cov}\left(\theta_{R S}, \theta_{C R N}\right)}{\sigma_{R S} \sigma_{C R N}} \\
& R M S E=\sqrt{\frac{1}{N} \sum_{i=1}^{N}\left(\theta_{R S}-\theta_{C R N}\right)_{i}^{2}} \\
& \text { bias }=\frac{1}{N} \sum_{i=1}^{N}\left(\theta_{R S}-\theta_{C R N}\right)_{i} \\
& \text { ubRMSE }=\sqrt{R M S E^{2}-\text { bias }^{2}}
\end{aligned}
$$

where $i$ denotes a given pair of estimates and measurements and $N$ is the total number of paired estimates and measurements. Since in most cases the location of CRN stations is not exactly located in the center of satellite RS pixels (MODIS, SMAP, SMOS, and ASCAT), we selected those satellite pixels that covered at least $50 \%$ of $\mathrm{CRN}$ footprint. This provides a reliable comparison between the estimated and measured soil moisture pairs.

\subsubsection{Drought Analysis}

Most of the proposed drought assessment indices are based on long-term atmospheric variables (Palmer, 1965; McKee et al., 1993; Hogg, 1994), but they do not consider soil moisture measurements, which are a direct measure of agricultural drought. One reason for this negligence is probably due to a lack of soil moisture monitoring networks in the past. Today, satellite data can provide soil moisture information with a wide range of spatial and temporal resolutions. MODIS satellite data provide an excellent long-term database for drought monitoring applications. With respect to its definition, agricultural drought is defined based on soil moisture deficit and its effect on crop production, i.e., when evapotranspirative losses exceed the plant available soil moisture defined as the difference between soil moisture at field capacity and that at permanent wilting point 
(Kabat and Beekman, 1994). Martinez-Fernandez et al. (2015) introduced a Soil Water Deficit Index (SWDI) for agricultural drought monitoring as follows:

$$
S W D I=10 \frac{\theta-\theta_{F C}}{\theta_{F C}-\theta_{P W P}}
$$

where $\theta_{F C}$ and $\theta_{P W P}\left(\mathrm{~cm}^{3} \mathrm{~cm}^{-3}\right)$ are soil moisture content at field capacity and permanent wilting point, respectively. Positive values of SWDI signify excess water in soil, while negative values indicate some degree of soil drought. When SWDI is equal to zero, it means the soil is at field capacity moisture content. The values equal to or smaller than -10 indicate that the moisture content is below the lower limit of available water for plants, i.e., extreme water deficit in soil (Martinez-Fernandez et al., 2015). As mentioned above, MODIS-OPTRAM soil moisture estimates can provide a long-term dataset for agricultural drought monitoring based on calculating SWDI (i.e., OPTRAM-SWDI). The $\theta_{F C}$ and $\theta_{P W P}$ were determined with the ROSETTA pedotransfer model (Schaap et al., 2001) that uses clay content, sand content, silt content, and bulk density data for parameterizing a soil water retention model (i.e., van Genuchten, 1980) and thereby determining $\theta_{F C}$ and $\theta_{P W P}$. These basic soil properties were extracted for each site from the global ISRIC Soil database (https://soilgrids.org) with a spatial resolution of $250 \mathrm{~m}$.

The Crop Moisture Index (CMI) (Palmer, 1968) which is related to soil water storage was used as reference to assess the accuracy of the OPTRAM-SWDI for agricultural drought monitoring. The daily CMI is inversely calculated based on the subtraction of daily potential evapotranspiration from daily precipitation $\left(P-E T_{0}\right)$, where the daily $E T_{0}$ was calculated based on the Thornthwaite method for each site (Thornthwaite, 1948; Rim, 2000).

\section{Results and Discussion}

\subsection{OPTRAM Parameters}


Figure 3 illustrates the pixel distribution within the STR-NDVI space together with the optimized dry and wet edges (fitted black lines) for each watershed. The uncertainty lines (colored lines) for the optimized dry and wet edges at levels $\pm \% 5, \pm \% 10, \pm \% 15$, and $\pm \% 20$ are also indicated in Fig. 3. As observed, a nearly trapezoidal shape is formed by STR-NDVI point clouds for each watershed based on the integration of all MODIS images listed in Table 2. Each of the four feature spaces exhibit a wide range of STR and NDVI values that may be due to the variability of soil moisture, diverse climate, soil type, and land cover. In general, STR and NDVI values are larger in regions with dense vegetation cover, e.g., Willow Creek and Big Cypress Creek watersheds (see also Fig. 2), which is due to high soil moisture and/or vegetation water content. The larger STR values in densely vegetated soils indicate higher moisture contents in the root zone. The visually optimized parameters for the dry and wet edges for each watershed are listed in Table 2. Table 3 summarized the variability range for each parameter at each uncertainty level for each watershed. As can be seen, a small change for each parameter is observed at levels $\pm \% 5$ to $\pm \% 20$ indicating a good fitting based on the visual inspection. Using these parameters, $W$ in Eq. (5) can be easily computed for any value of STR and NDVI.

Table 2. The dry and wet edge parameters [Eq. (5)] obtained for each watershed based on long-term MODIS satellite data.

\begin{tabular}{lccccccc}
\hline \multirow{2}{*}{ Watershed, State } & \# MODIS & & \multicolumn{2}{c}{ Dry edge } & & \multicolumn{2}{c}{ Wet edge } \\
\cline { 7 - 8 } & images & & $i_{d}$ & $S_{d}$ & & $i_{w}$ & $S_{w}$ \\
\hline Walnut Gulch (WGW), AZ & 543 & & 0.10 & 2.60 & & 2.50 & 1.70 \\
Willow Creek (WCW), CA & 750 & & 0.00 & 2.80 & & 1.50 & 10.0 \\
Reynolds Creek (RCW), ID & 450 & & 0.23 & 1.10 & & 3.00 & 5.50 \\
Big Cypress Creek (BCCW), GA & 560 & & 0.00 & 0.70 & & 0.00 & 19.0 \\
\hline
\end{tabular}


Table 3. The variability range of the dry and wet edge parameters (from Table 2) at four uncertainty levels for each watershed based on long-term MODIS satellite data. The values are the average of four replicates, i.e. R1, R2, R3, R4.

\begin{tabular}{|c|c|c|c|c|c|}
\hline \multirow{2}{*}{ Watershed, State } & \multirow{2}{*}{$\begin{array}{c}\text { Uncertainty } \\
\text { level }\end{array}$} & \multicolumn{2}{|c|}{ Dry edge } & \multicolumn{2}{|c|}{ Wet edge } \\
\hline & & $i_{d}$ & $S d$ & $i_{w}$ & $S_{w}$ \\
\hline \multirow[t]{4}{*}{ Walnut Gulch (WGW), AZ } & $\pm \% 5$ & 0.10 & 2.57 & 2.54 & 1.70 \\
\hline & $\pm \% 10$ & 0.10 & 2.67 & 2.53 & 1.70 \\
\hline & $\pm \% 15$ & 0.09 & 2.58 & 2.70 & 1.76 \\
\hline & $\pm \% 20$ & 0.10 & 2.66 & 2.44 & 1.64 \\
\hline \multirow[t]{4}{*}{ Willow Creek (WCW), CA } & $\pm \% 5$ & 0.0 & 2.76 & 1.52 & 10.04 \\
\hline & $\pm \% 10$ & 0.0 & 2.83 & 1.53 & 9.90 \\
\hline & $\pm \% 15$ & 0.0 & 2.74 & 1.48 & 10.04 \\
\hline & $\pm \% 20$ & 0.0 & 2.87 & 1.54 & 9.08 \\
\hline \multirow[t]{4}{*}{ Reynolds Creek (RCW), ID } & $\pm \% 5$ & 0.23 & 1.09 & 2.98 & 5.56 \\
\hline & $\pm \% 10$ & 0.23 & 1.15 & 3.07 & 5.29 \\
\hline & $\pm \% 15$ & 0.22 & 1.09 & 2.97 & 5.51 \\
\hline & $\pm \% 20$ & 0.25 & 1.17 & 2.97 & 5.54 \\
\hline \multirow{4}{*}{$\begin{array}{l}\text { Big Cypress Creek (BCCW), } \\
\text { GA }\end{array}$} & $\pm \% 5$ & 0.0 & 0.706 & 0.0 & 18.6 \\
\hline & $\pm \% 10$ & 0.0 & 0.682 & 0.0 & 18.9 \\
\hline & $\pm \% 15$ & 0.0 & 0.726 & 0.0 & 20.5 \\
\hline & $\pm \% 20$ & 0.0 & 0.636 & 0.0 & 19.7 \\
\hline
\end{tabular}




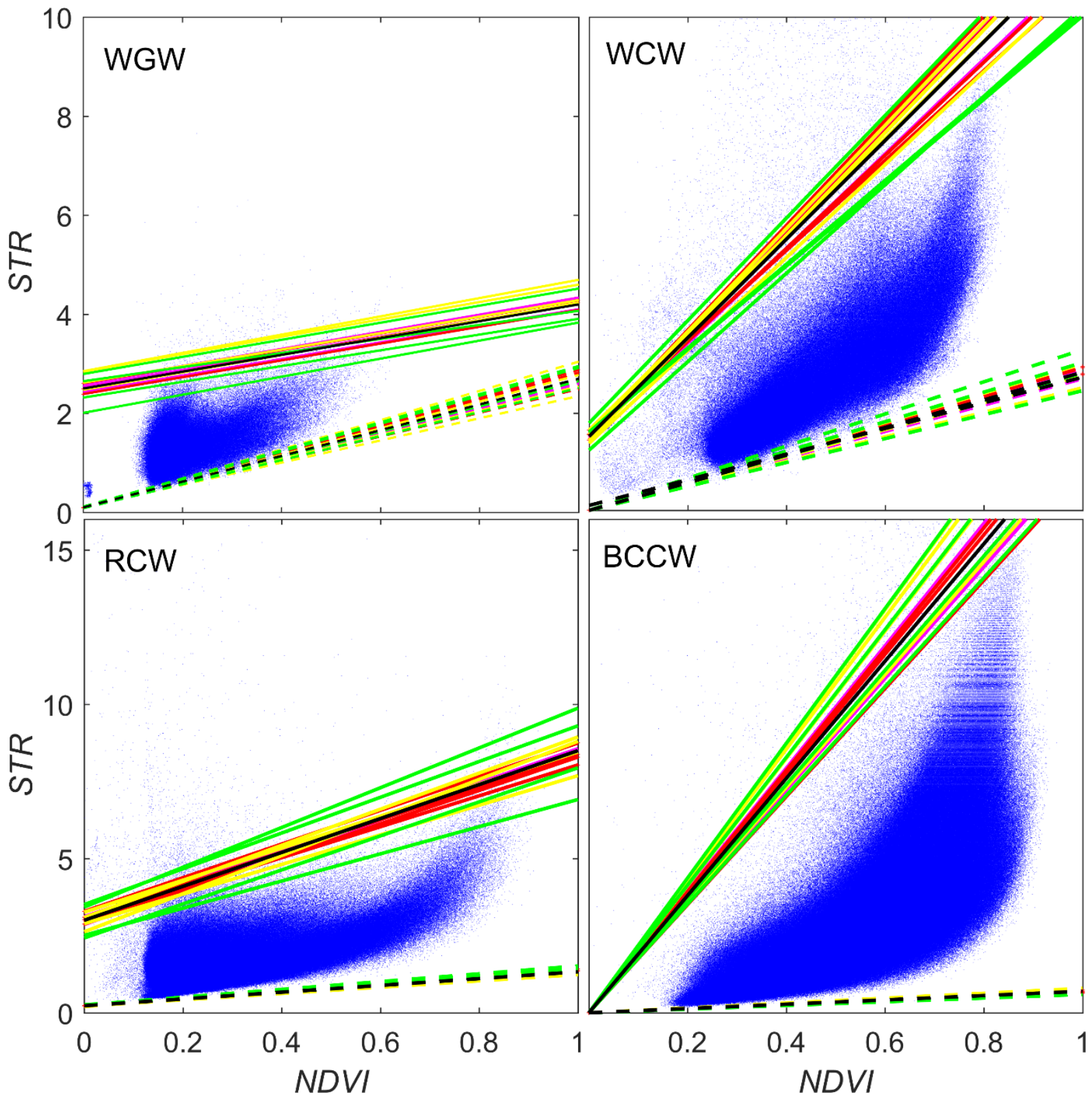

Fig. 3. Pixel distribution within the STR-NDVI space formed by long-term MODIS data (20012017) for the Walnut Gulch Watershed (WGW), Willow Creek Watershed (WCW), Reynolds Creek Watershed (RCW), and Big Cypress Creek Watershed (BCCW). The solid and dashed black lines indicate the original fitted wet and dry edges, respectively. The colored lines indicate uncertainty in the original fitted dry and wet edges at levels $\pm \% 5$ (magenta with 4 replicates), $\pm \% 10$ (red with 4 replicates), $\pm \% 15$ (yellow with 4 replicates), and $\pm \% 20$ (green with 4 replicates).

\subsection{Sensitivity of OPTRAM parameters to visual fitting}

The original fitted dry and wet edges may not well estimate the actual soil moisture content across the study sites because the dry and wet edges were determined through visual fitting of a straight 
line to the point clouds within the STR-NDVI space that adds uncertainties in soil moisture estimation. Also, different users may obtain distinct dry and wet edges visually. To quantify the accuracy of visual fitting on soil moisture estimation, a sensitivity analysis was carried out by testing the response of soil moisture estimates at CRN pixels to OPTRAM optimized parameters at each uncertainty level listed in Table 3. Figure 4 depicts correlation between OPTRAM soil moistures for these two parameter sets. In general, strong correlations are observed for all the uncertainty levels. The small deviations are for levels $\pm \% 5$ and $\pm \% 10$, and the largest for $\pm \% 20$, particularly in WGW in Arizona and RCW in Idaho. The average RMSE values at levels $\pm \% 5$, $\pm \% 10, \pm \% 15$, and $\pm \% 20$ for all the sites are $0.007,0.010,0.012$, and $0.025 \mathrm{~cm}^{3} \mathrm{~cm}^{-3}$, respectively, indicating reasonable accuracy of visually-based fitting of the dry and wet edges in estimation of soil moisture using OPTRAM. 


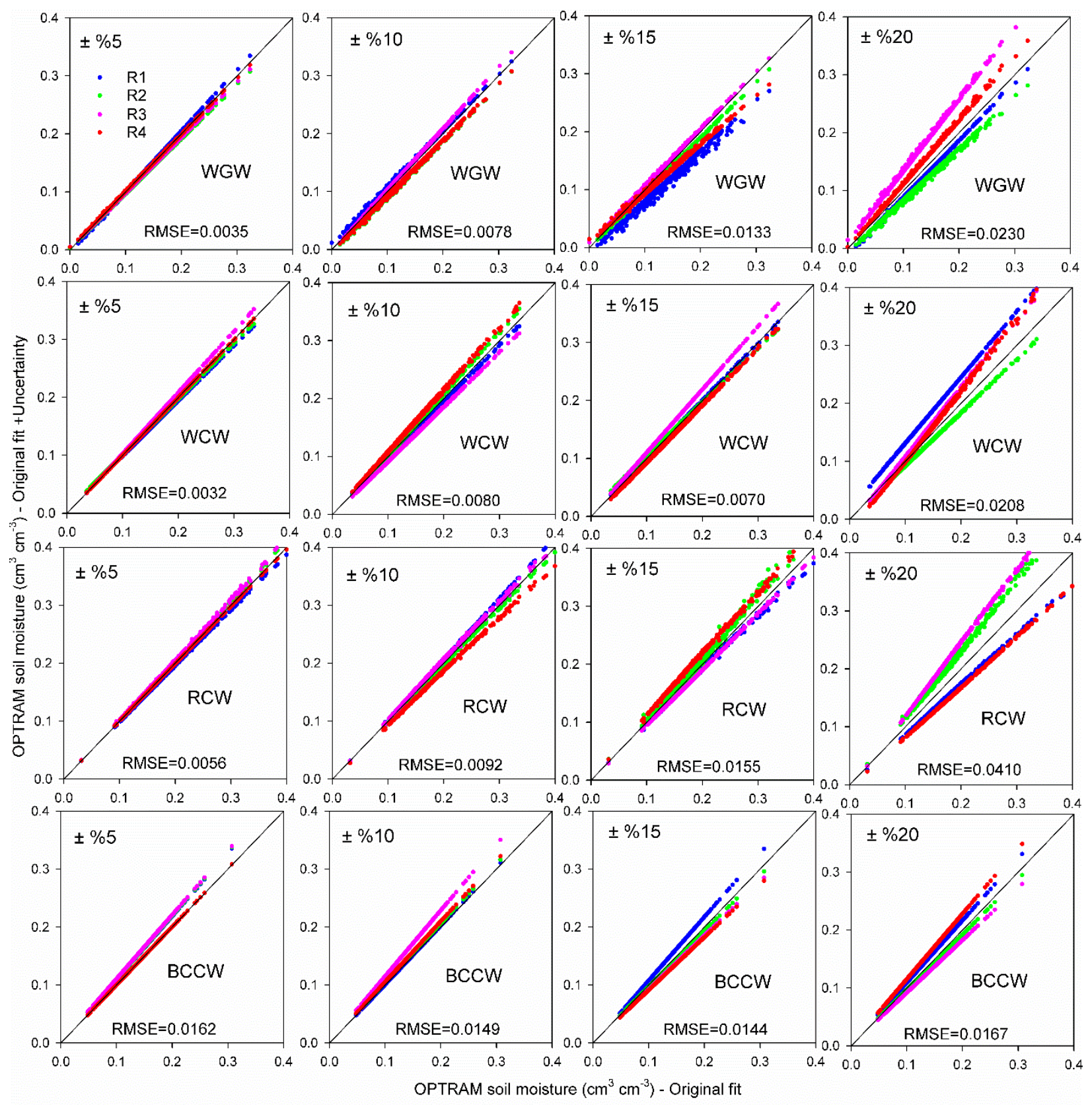

Fig. 4. Scatterplots depicting OPTRAM soil moisture estimates at CRN sites based on dry and wet edge original fit versus those based on various levels of parameter uncertainty $( \pm \% 5, \pm \% 10, \pm \% 15$, and $\pm \% 20$ ) (4 replicates, R1, R2, R3, R4) for sites Kendal, AZ (WGW), Tonzi ranch, CA (WCW), Reynolds Creek, ID (RCW), and JERC, GA (BCCW). RMSE is average of root mean squared error for the 4 replicates. 


\subsection{Rescaled CDFs}

Comparisons between the original and rescaled CDFs of CRN reference soil moisture data and soil moisture estimates from OPTRAM, SMAP, SMOS, and ASCAT for each site and for all dates are illustrated in Fig. 5. A large mismatch is shown between the original CDFs, while the rescaled CDFs coalesced well. This result indicates that the different sources resulted in different, but highly-correlated, soil moisture values. One probable reason for the observed mismatch could be the spatial scale mismatch, i.e., different image pixel size and sensing volume. As seen in Fig. 5, ASCAT tends to produce lower soil moisture values for most sites. For example, at the Kendal and Lucky Hills sites, the ASCAT soil moisture estimates indicate very dry conditions $\left(<0.05 \mathrm{~cm}^{3}\right.$ $\mathrm{cm}^{-3}$ ) during most of the dry season, while OPTRAM never reached values that low. The highest soil moisture values in most sites were reported by either OPTRAM or SMAP, which could be due to their deeper sensing depth, i.e., deeper penetration of SMAP's L-band and OPTRAM's responsiveness to plant canopy-derived root zone soil moisture. As mentioned, the rescaled CDFs for the remotely sensed soil moisture data were well matched to CRN soil moisture data at all four sites, leading to reduced error metrics such as RMSE and bias. However, it should be noted that the correlation coefficient $(R)$ will not change due to CDF matching, as CDF matching is basically a linear transformation of the original data and has nothing to do with random variations that determine $R$. 


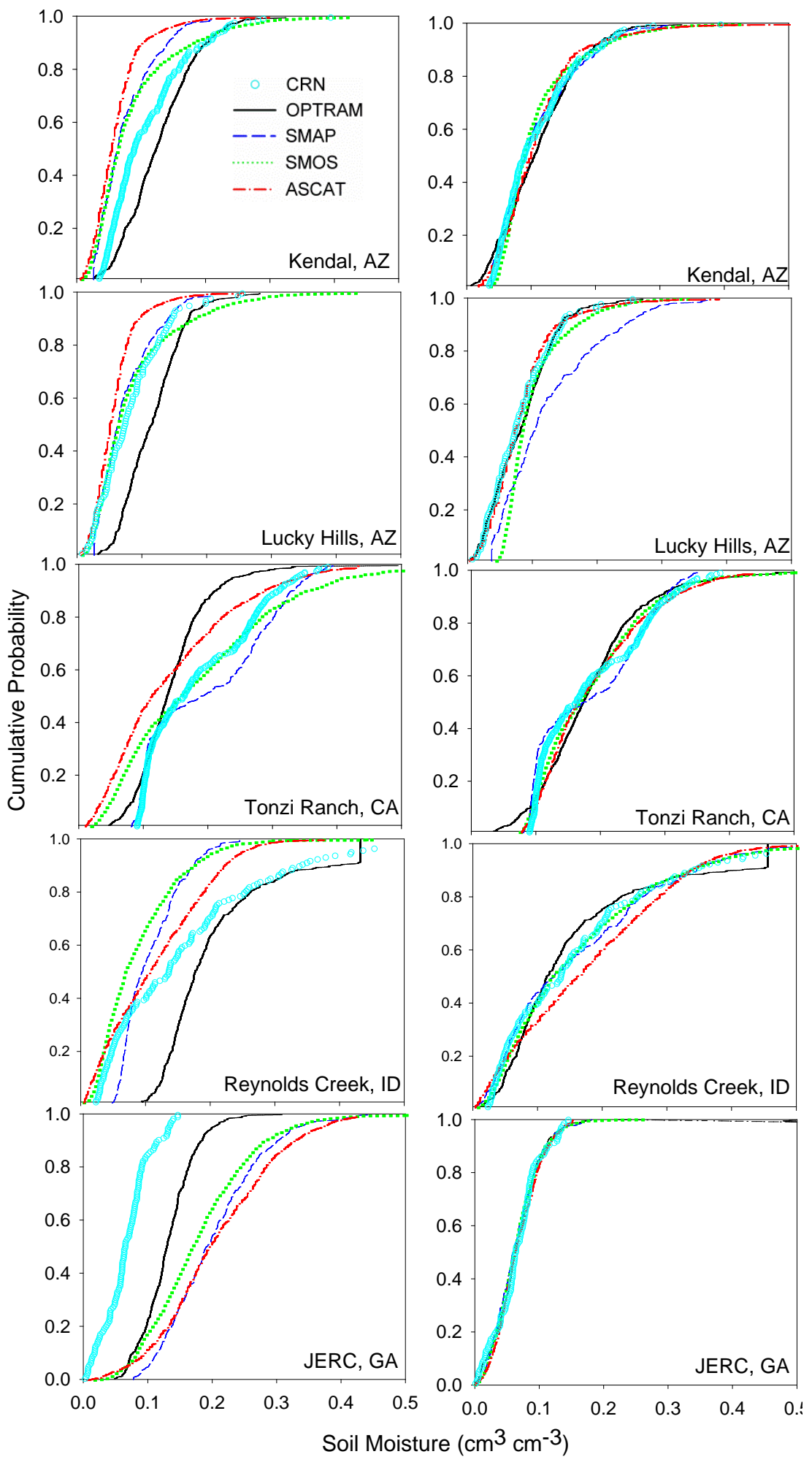

Fig. 5. Cumulative Probability for matching the CDFs based on CRN data, original (left column) and rescaled (right column) remote sensing-based estimates of soil moisture from OPTRAM, SMAP, SMOS, and ASCAT for sites Kendal, AZ; Lucky Hills, AZ; Tonzi Ranch, CA; Reynolds Creek, ID; and JERC, GA. 


\subsection{Soil Moisture Estimates}

Figure 6 depicts a comparison of OPTRAM-derived soil moisture daily temporal dynamics with those of CRN, SMAP, SMOS and ASCAT from 2010 to 2017. The OPTRAM estimates exhibit distinct dry and wet cycles and capture the dynamics of CRN soil moisture at the five selected sites, especially at Tonzi Ranch and Reynolds Creek, indicating good performance of OPTRAM (mean ubRMSE value of 0.0675 and mean $R$ value of 0.3940 ). Data shown in Fig. 5 clearly demonstrate distinct differences in climate, land cover and soil variability among the four watersheds. Compared to the other three sites, the range of OPTRAM and CRN soil moisture is limited at Kendal and Lucky Hills (Walnut Gulch) sites because these two sites have a semi-arid climate with well-drained coarse-textured soils and limited precipitation. A wider range of soil moisture content is evident for Tonzi Ranch and Reynolds Creek, which is associated with more frequent precipitation events during each season and also the existence of clay loam and silty soils across these two sites. In addition, a wider range of OPTRAM soil moisture compared to CRN observations is also evident at each site during the studied period, especially for humid climates. This is partly due to the higher noise of the satellite-based estimates compared with the noise of ground (CRN) measurements. Another physical reason, especially for bare soils, is that OPTRAMbased estimates represent the surface (skin) soil moisture for a thin layer with a few mm depth, whereas CRN data provide effective soil moisture down to about $50 \mathrm{~cm}$ for nearly dry soils (Zreda et al., 2012). This fact results in remotely sensed soil moisture values to be more responsive to atmospheric factors (i.e., precipitation, radiation, and evaporative demand), explaining the high temporal variability and dynamic range of surface soil moisture. The CRN soil moisture values 
are generally higher during summer and dry periods. This result is mainly due to the neglected effect of high biomass growth rate affecting CRN-based soil moisture (Andreasen et al., 2017).

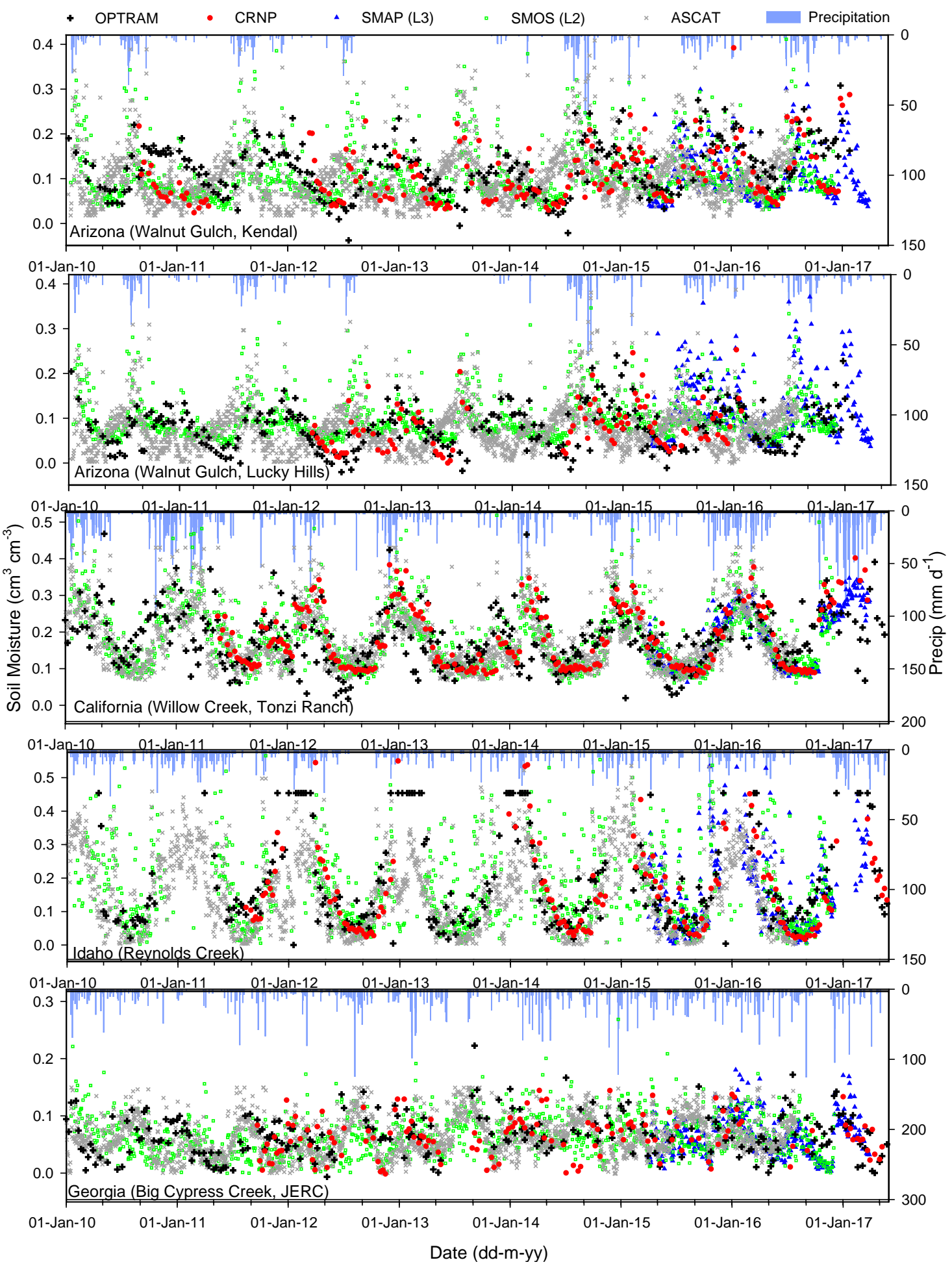


Fig. 6. Time series of remotely sensed (OPTRAM, SMAP, SMOS, ASCAT) and CRN-based soil moisture and precipitation at Kendal, AZ; Lucky Hills, AZ; Tonzi Ranch, CA; Reynolds Creek, ID, and JERC, GA. The precipitation data were extracted from SNOTEL (SNOwpack TELemetry) and SCAN (Soil Climate Analysis Network) sites closest to each CRN station. Note that for the Walnut Gulch sites, no precipitation was recorded by the SCAN rain gauges from August 2012 to November 2013.

In Fig. 6, rescaled OPTRAM soil moisture estimates are also compared with rescaled soil moisture retrievals from SMAP, SMOS, and ASCAT. As seen, OPTRAM estimates follow the seasonal variations of SMAP, SMOS, and ASCAT retrievals. Although a similar overall pattern is observed, the OPTRAM values are generally lower, especially during warmer periods. During or shortly after a precipitation event, OPTRAM data are quite noisy which may be due to low quality MODIS optical images resulting from cloud and atmospheric water vapor effects.

The original ASCAT, SMOS, and SMAP soil moisture retrievals (not presented here) were much more variable showing a wider range of values than those of OPTRAM and CRN for most sites. This greater variability may primarily be due to the different sensing depths of microwaves, which are known to be shallower for shorter wavelengths. For instance, C-band ASCAT is sensitive down to a $2 \mathrm{~cm}$ depth and can be even less than $1 \mathrm{~cm}$ during a strong rainfall event, whereas L-band SMOS penetrates to about $5 \mathrm{~cm}$ (Al-Yaari et al., 2014). Therefore, during and shortly after a precipitation event, microwave soil moisture retrievals associated with a very wet surface layer show higher soil moisture values than CRN data, whose penetration depth exceeds $15 \mathrm{~cm}$. This discrepancy between microwave and CRN data is reduced with time after precipitation because the soil profile tends toward a more uniform moisture distribution. Another reason for the observed discrepancies could be due to high spatial soil moisture variability after intense precipitation events (also spatially variable), magnifying effects of the scale mismatch between lower resolution microwave and higher resolution CRN observations. For some cases, for example in Arizona sites, a time lag in ASCAT soil moisture data compare with the other soil moisture 
estimation methods is observed for soil moisture values smaller than $0.20 \mathrm{~cm}^{3} \mathrm{~cm}^{-3}$. This time lag may be attributed to change in surface roughness and land cover within the scatterometer measurement pixel that has been assumed to be stable in time based on ASCAT retrieval algorithm (WARP). The lag in summer may relate to the increase in vegetation cover and thereby decrease in soil moisture content due to water uptake by plant.

Scatterplots between CRN-derived and remotely-sensed soil moisture estimates for each site are presented in Fig. 7. Correlations between the CRN estimates and rescaled OPTRAM and microwave satellite soil moisture estimates range between 0.100 and 0.927 . Based on RMSE estimates, SMAP and SMOS performed better than OPTRAM and ASCAT except for the Reynolds Creek site. This was generally expected since microwave signals at lower frequencies (L-band) are much more sensitive to soil water (i.e., dielectric constant) and microwave-based retrievals provide more accurate soil moisture estimates than optical methods. In our study, comparison of OPTRAM estimates with ASCAT retrievals (C-band) over all sites indicate that OPTRAM performed similar to or better than ASCAT for all sites, except for the JERC site in GA. 

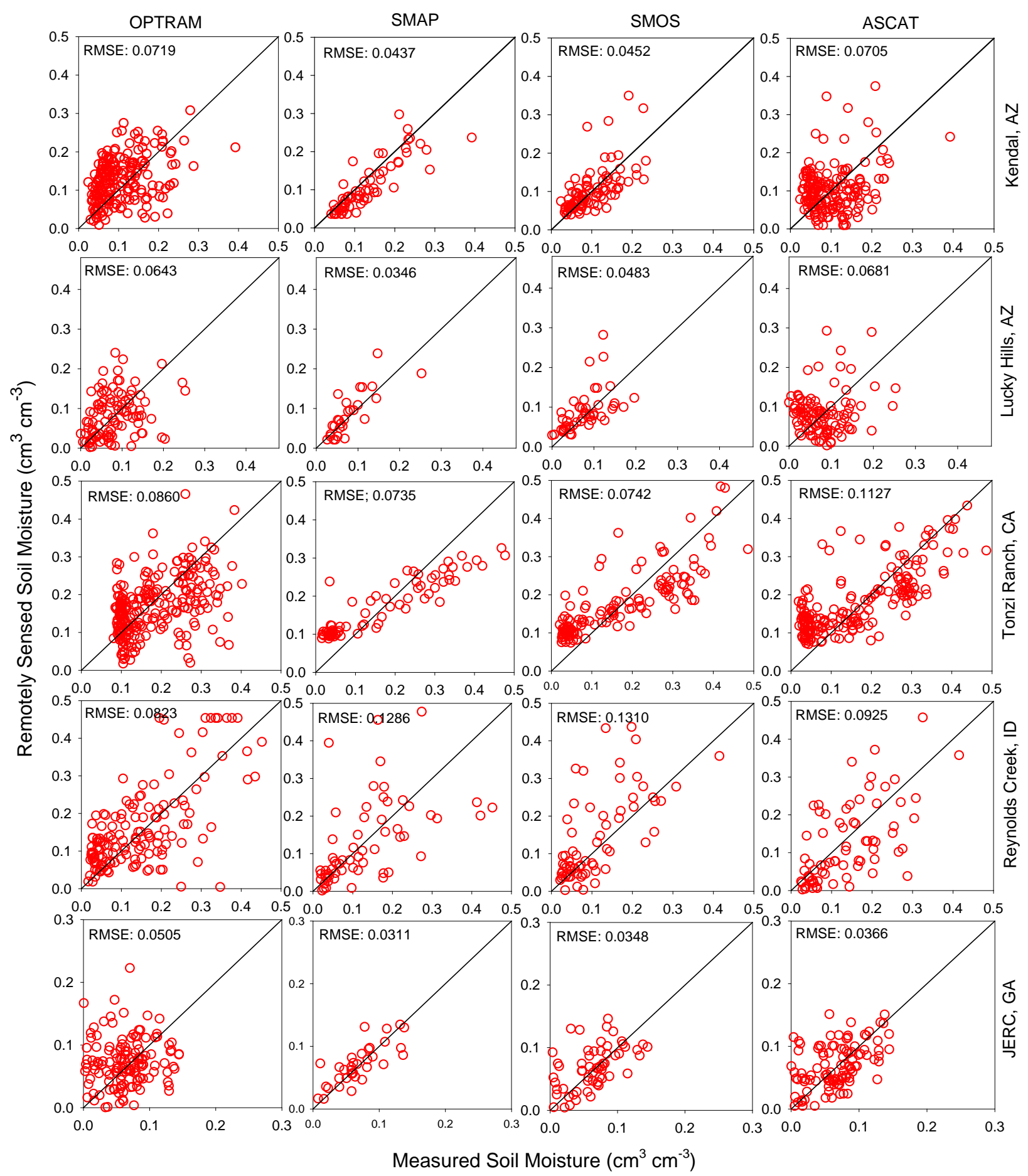

Fig. 7. Scatterplots comparing remotely sensed (OPTRAM, SMAP, SMOS, and ASCAT) with CRN-based soil moisture for Kendal, AZ; Lucky Hills, AZ; Tonzi Ranch, CA; Reynolds Creek, ID, and JERC, GA. 
Table 4 compares soil moisture estimation performance of OPTRAM and microwave satellites with CRN estimates in terms of $R, R M S E$, unRMSE, and bias for each site. These error metrics indicate a generally good agreement between the OPTRAM and CRN estimates. OPTRAM yields slightly larger RMSE values than SMAP and SMOS, but equal to or better than ASCAT for most sites. At Kendal, Lucky Hills and JERC, OPTRAM performed well with RMSE and $u b R M S E$ close to ASCAT. OPTRAM yielded $u b R M S E$ values between 0.0501 to $0.0853 \mathrm{~cm}^{3}$ $\mathrm{cm}^{-3}$ and $R$ values between 0.100 and 0.746 when compared with CRN. At the JERC site in GA, OPTRAM shows the best agreement with CRN, where ubRMSE was 0.0501 and bias was 0.0066 $\mathrm{cm}^{3} \mathrm{~cm}^{-3}$. At all sites except Tonzi Ranch, OPTRAM overestimated soil moisture with an average bias of $0.019 \mathrm{~cm}^{3} \mathrm{~cm}^{-3}$. This overestimation was referred to as an 'oversaturated issue' in the original OPTRAM model development (Sadeghi et al., 2017), explained as the result of temporary shallow surface ponding and/or canopy interception of water, which increase STR values for a given NDVI and thereby overestimate soil moisture content. At Tonzi Ranch, OPTRAM slightly underestimated soil moisture with a bias of $-0.011 \mathrm{~cm}^{3} \mathrm{~cm}^{-3}$.

Table 4. Performance metrics for evaluation of OPTRAM, SMAP, SMOS, and ASCAT soil moisture estimates based on CRN observations at each of the investigated sites.

\begin{tabular}{llcccc}
\hline $\begin{array}{l}\text { COSMOS } \\
\text { site }\end{array}$ & Metric & OPTRAM & SMAP & SMOS & ASCAT \\
\hline Kendal, & bias & 0.0186 & -0.0216 & 0.0025 & 0.0015 \\
AZ & ubRMSE & 0.0695 & 0.0380 & 0.0451 & 0.0705 \\
& RMSE & 0.0719 & 0.0437 & 0.0452 & 0.0705 \\
& $R$ & 0.3533 & 0.8522 & 0.6464 & 0.2629 \\
& $N$ & 201 & 63 & 96 & 172 \\
Lucky & bias & 0.0399 & 0.0069 & 0.0081 & 0.0015 \\
Hills, AZ & ubRMSE & 0.0504 & 0.0339 & 0.0476 & 0.0680 \\
& RMSE & 0.0643 & 0.0346 & 0.0483 & 0.0681 \\
& $R$ & 0.3098 & 0.7892 & 0.5591 & 0.1609 \\
& $N$ & 108 & 28 & 49 & 101 \\
Tonzi & bias & -0.0109 & 0.0065 & 0.0098 & -0.0076 \\
Ranch, CA & ubRMSE & 0.0853 & 0.0732 & 0.0735 & 0.1125 \\
& RMSE & 0.0860 & 0.0735 & 0.0742 & 0.1127 \\
& $R$ & 0.461 & 0.927 & 0.814 & 0.752 \\
& $N$ & 244 & 74 & 134 & 206
\end{tabular}




\begin{tabular}{llcccc} 
& bias & 0.0109 & -0.0070 & 0.0519 & -0.0094 \\
Reynolds & ubRMSE & 0.0822 & 0.1284 & 0.1203 & 0.0921 \\
Creek, ID & RMSE & 0.0823 & 0.1286 & 0.1310 & 0.0925 \\
& $R$ & 0.7460 & 0.5041 & 0.6026 & 0.6104 \\
& $N$ & 177 & 64 & 72 & 73 \\
& bias & 0.0066 & -0.0015 & 0.0074 & 0.0015 \\
JERC, GA & ubRMSE & 0.0501 & 0.0310 & 0.0340 & 0.0365 \\
& RMSE & 0.0505 & 0.0311 & 0.0348 & 0.0366 \\
& $R$ & 0.1000 & 0.7829 & 0.5123 & 0.4977 \\
& $N$ & 139 & 36 & 65 & 109 \\
\hline
\end{tabular}

$N$ : the number of data pairs used to calculate metrics.

In theory, the ASCAT sensor should provide more accurate retrievals of soil moisture owing to the greater sensitivity of active microwave reflections to dielectric permittivity of soil water. The relatively large errors observed for ASCAT (compared to SMAP and SMOS) is consistent with several studies. Peng et al. (2015) found RMSE value 0.096 and bias value -0.053 $\mathrm{cm}^{3} \mathrm{~cm}^{-3}$ for ASCAT soil moisture retrievals for southwestern China. Rotzer et al. (2014) obtained RMSE values between 0.07 and $0.09 \mathrm{~cm}^{3} \mathrm{~cm}^{-3}$ and an $R$ value 0.25 for ASCAT for agricultural lands within the Ruhr catchment in Germany, and Djamai et al. (2015) reported RMSE values ranging from 0.07 to 0.11 and $R$ values from 0.10 to 0.37 for ASCAT for agricultural land and forests in Canada. In conformity with Montzka et al. (2017), the lowest error metrics are found for the SMAP and SMOS retrievals with very similar $R$ values but somewhat larger $u b R M S E$ values, likely due to the number of data points, study period, and use of corrected CRN data [see Eq. (6)]. Considering five site averages, the SMAP retrievals provide the highest $R(0.77)$ and lowest ubRMSE $\left(0.061 \mathrm{~cm}^{3} \mathrm{~cm}^{-3}\right)$ values followed by SMOS retrievals $(R=0.63$ and $u b R M S E=0.064$ $\left.\mathrm{cm}^{3} \mathrm{~cm}^{-3}\right)$, and ASCAT products $\left(R=0.40\right.$ and $\left.u b R M S E=0.076 \mathrm{~cm}^{3} \mathrm{~cm}^{-3}\right)$. At the Kendal, Lucky Hills and JERC sites, both SMAP and SMOS soil moisture retrievals fall within the mission target accuracy of $0.04 \mathrm{~cm}^{3} \mathrm{~cm}^{-3}$. 
Considering data bias, SMAP tends to slightly underestimate soil moisture at Kendal, Reynolds Creek, and JERC and the ASCAT underestimates soil moisture at Tonzi Ranch and Reynolds Creek. Underestimations for SMAP may arise from the smaller sensing depth and larger radiometer footprint compared with CRN measurements, as discussed above. For ASCAT the underestimation could additionally be due to the uncertainty in soil porosity when the relative saturation (values between 0 and 1) is converted to volumetric moisture content. The underestimation could also be due to bias in CRN measurements. For instance, the Tonzi Ranch site is located in a flat area where the CRN footprint is subject to water ponding after heavy precipitation events, resulting in higher CRN soil moisture values. At the Reynolds Creek site located in a mountainous area, the CRN footprint includes a surface layer of snow during the winter. This can result in soil moisture estimates exceeding the soil porosity, as indicated in Fig. 6.

At the JERC site, remotely sensed data exhibit the smallest bias scores, which may arise from the narrow range of soil moisture dynamics. For instance, OPTRAM shows $R$ equal to 0.10 but $u b R M S E$ equal to $0.0501 \mathrm{~cm}^{3} \mathrm{~cm}^{-3}$. This result indicates that the use of these standard metrics is not always suitable for in-depth evaluation of soil moisture accuracy. The correlation between in situ soil moisture and satellite observations is commonly not very large and a typical $R$ range between 0.40 to 0.80 is reported, but even a complete lack of correlation does not necessarily mean that the satellite based estimations are wrong (Wagner et al., 2013). In such a case, as we have done in this study, it is more appropriate to interpret remote sensing results in a relative context for example by comparing with performance of other satellite data against the same reference data rather than attributing absolute meaning to the results (Wagner et al., 2013). 


\subsection{Drought Indices}

As mentioned earlier, long-term MODIS data can provide a historical database of soil moisture estimates preceding the launch of microwave satellites. This long-term database is a valuable asset for an array of applications such as agricultural drought assessment and climate studies. To check the performance of OPTRAM for this application, SWDI was computed based on OPTRAM estimates and compared with an atmospheric drough index, CMI. Weekly SWDI temporal dynamics based on OPTRAM soil moisture estimates for our five selected sites are compared with CMI values in Fig. 8 (left). In this study, the OPTRAM-SWDI approach is similar to Mishra et al. (2017) and Martinez-Fernandez et al. (2016), who used SMAP and SMOS soil moisture retrievals to compute SWDI to monitor agricultural drought, respectively. A similar pattern is observed between OPTRAM-SWDI and CMI at all sites except the Big Cypress Creek, which shows large discripancies over the whole period in terms of temporal evolution and identification of drought onsets. This mismatch may arise from the narrow range of soil moisture in what is a predominantly sandy textured soil of the Big Cypress Creek (see Fig. 6). The relatively low water storage capacity ( $\theta_{F C}$ and $\theta_{P W P}$ equal to 0.13 and 0.05 respectively) limits plant soil moisture availability, producing larger differences in calculated soil moisture based on CMI (i.e., $P-E T_{0}$ ). The OPTRAM-SWDI is an indicator of water availability in soil, which can be used to estimate agricultural drought. 

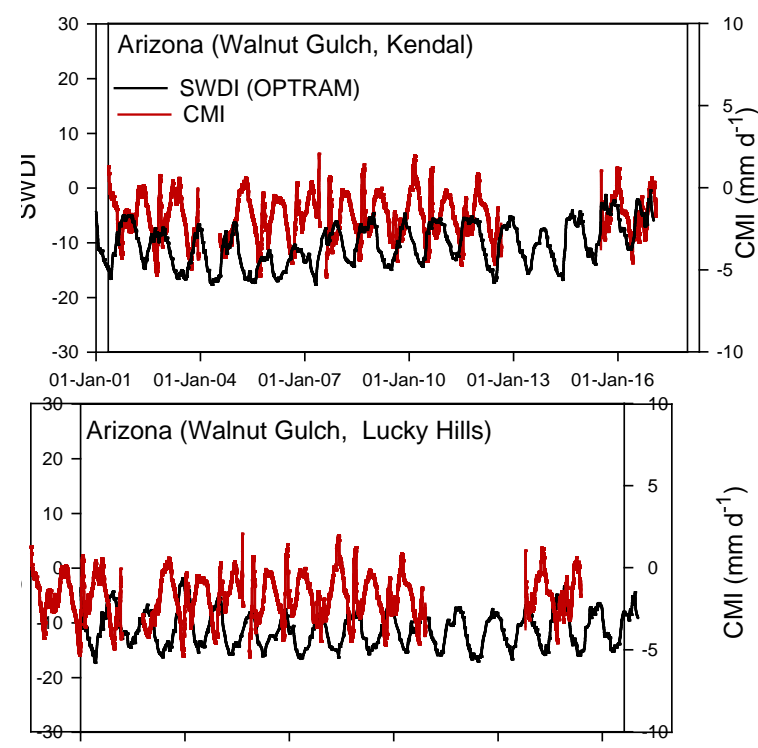

01-Jan-01 01-Jan-04 01-Jan-07 01-Jan-10 01-Jan-13 01-Jan-16

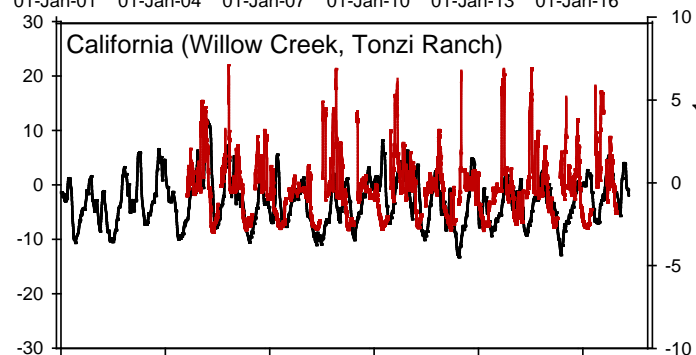

01-Jan-01 01-Jan-04 01-Jan-07 $\quad$ 01-Jan-10 $\quad$ 01-Jan-13 $\quad$ 01-Jan-16

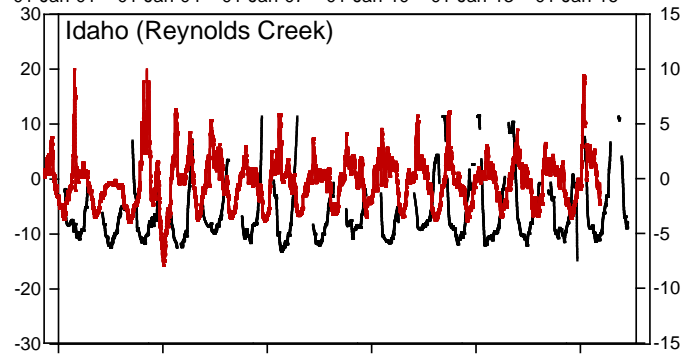

01-Jan-01 01-Jan-04 01-Jan-07 01-Jan-10 01-Jan-13 01-Jan-16

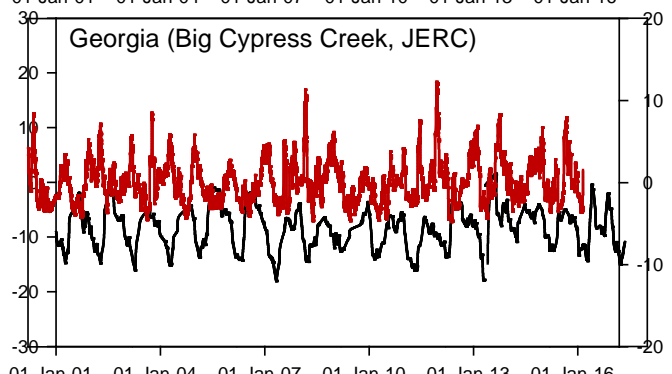

01-Jan-01 01-Jan-04 01-Jan-07 01-Jan-10 01-Jan-13 01-Jan-16

Date (dd-m-yy)

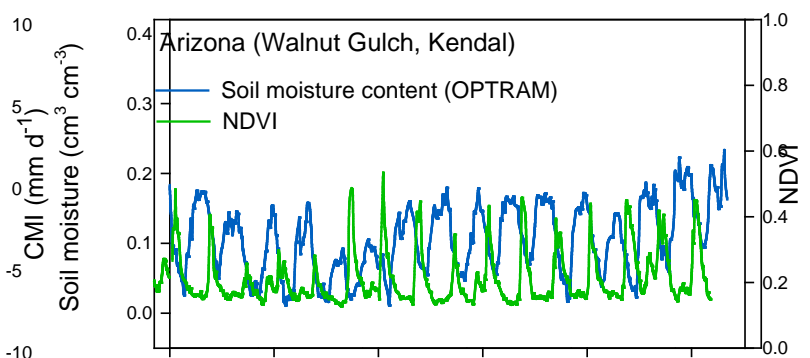

01-Jan-01 01-Jan-04 01-Jan-07 01-Jan-10 01-Jan-13 01-Jan-16

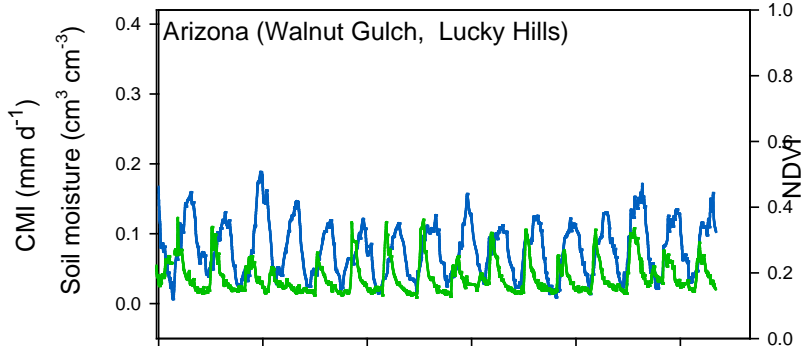

01-Jan-01 01-Jan-04 01-Jan-07 01-Jan-10 01-Jan-13 01-Jan-16

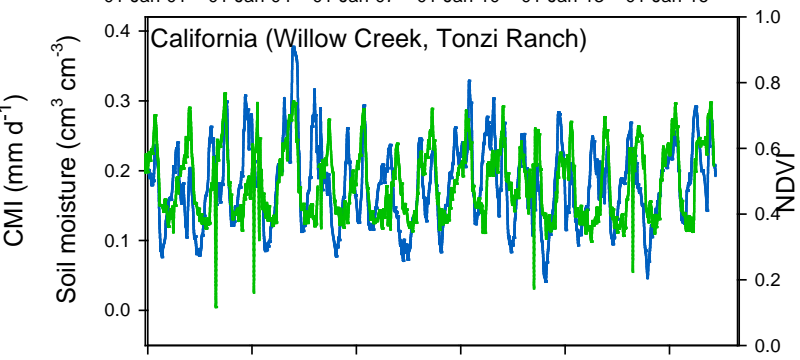

01-Jan-01 01-Jan-04 01-Jan-07 $\quad$ 01-Jan-10 $\quad$ 01-Jan-13 $\quad$ 01-Jan-16
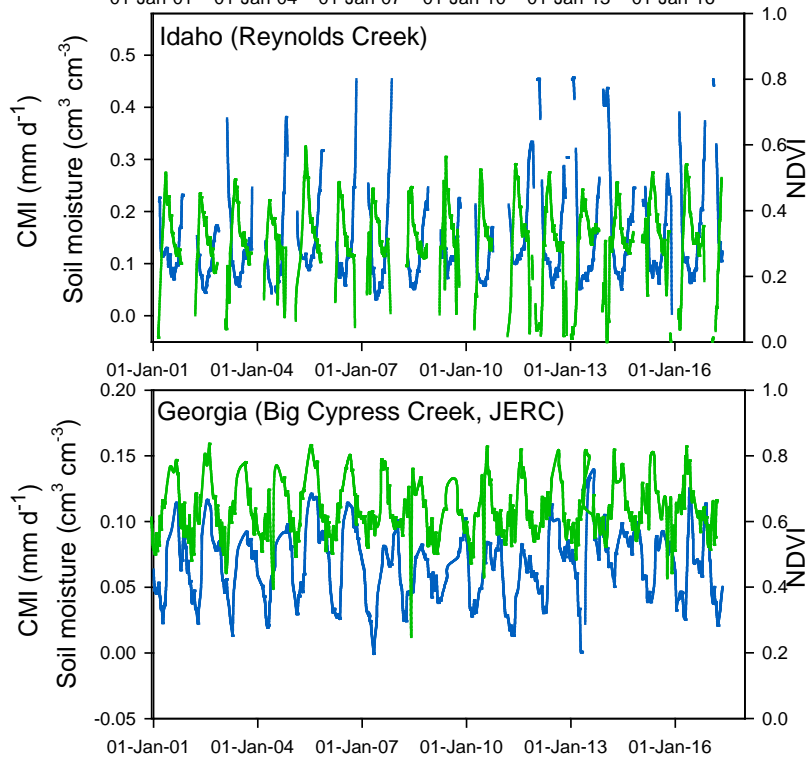

Date (dd-m-yy)

Fig. 8. Temporal dynamics of weekly OPTRAM-SWDI compared with CMI (left), and OPTRAM-based soil moisture and NDVI values (right) for five sites. 
Figure 8 (right) provides a comparison betweeen OPTRAM soil moisture and NDVI time series for each site for the 2001 to 2017 period. It is obvious that OPTRAM soil moisture and NDVI show similar temporal evolution for the dry and wet periods (with a small time lag), which is related to the response of vegetation to soil moisture content. The OPTRAM soil moisture and NDVI also show similar patterns with the corresponding OPTRAM-SWDI and CMI values at each site. The NDVI and other similar vegetation indices such as Soil Adjusted Vegetation Index (SAVI by Huete, 1988) and Enhanced Vegetation Index (EVI by Liu and Huete, 1995) have been widely used for drought monitoring through correlation with other climatic drought indicators. However, NDVI anomalies may show time lags of several weeks with atmospheric variables (e.g., precipitation as discussed by Zhang et al., 2013) that restrict the application of NDVI for drought monitoring, as is also evident in Fig. 8 (right).

Based on OPTRAM-SWDI values, all sites have experienced a wide range of drought severity from no drought (SWDI $\geq 0$ ) to extreme drought (SWDI $\leq-10$ ) during the 2001 to 2017 period. In general, drought events are clearly captured by OPTRAM-SWDI based on higher negative values. For example in Arizona, a significant deficit of precipitation from May 2002 to October 2004 and February 2006 to November 2007 led to severe and extreme drought conditions evidenced by OPTRAM-SWDI values that reduced to around -17 and daily CMI values that reduced to around -5 . This drought pattern coincides with the U.S. Drought Monitor data (https://droughtmonitor.unl.edu) in Arizona where more than 50\% of the state area experienced exceptional and extreme drought conditions during this period (data are not shown). These results are promising and indicate the importance of long-term MODIS data (since 2000) for generating historical long-term soil moisture dynamics with the OPTRAM approach to show agricultural drought periods, particularly in regions where soil moisture information is lacking. This could also 
potentially provide means for long-term (decadal-scale) drought monitoring based on OPTRAMMODIS soil moisture information, which is key to developing early warning systems for agricultural drought.

A critical issue of soil moisture estimation from optical satellite data is that estimates are limited to the surface soil layer (i.e., a few mm). Agricultural drought is related to soil water availability for plants, water which is mainly stored in the deeper root zone layer. However, strong correlations exist between surface (or near-surface) and root zone soil moisture (Albergel et al., 2008; Hirschi et al., 2014). With OPTRAM, it is assumed that $\theta$ (or $W$ ) in Eq. (5) is correlated to root zone soil moisture through the vegetation response to soil water deficit in the root zone layer (Sadeghi et al., 2017). Many other studies have tracked the change in root zone soil moisture via remotely sensed vegetation indices because soil moisture status in the root zone influences the vegetation water content and thereby changes the spectral characteristics of the vegetation (Santos et al., 2014). These findings suggest that OPTRAM soil moisture estimates can be directly used for agricultural drought monitoring and would be a suitable alternative for coarse resolution microvawe-based soil moisture retrievals, which are currently too coarse for drought monitoring over agricultural fields.

\section{Summary and Conclusions}

This paper presents a comprehensive evaluation of the optical trapezoid model (OPTRAM) accuracy for estimation of soil moisture. The evaluation includes four distinct watersheds in the U.S., which are diverse in climate and land cover. Long-term MODIS images from 2001-2017 were employed to obtain a universal parameterization of the OPTRAM model for estimation of soil moisture. Accuracy of the optimized dry and wet edges were tested using a sensitivity analysis. Cosmic-ray neutron (CRN) soil moisture data from the U.S. COSMOS network, as well as three 
other existing satellite-based surface soil moisture products, including SMAP, SMOS, and ASCAT retrievals, were used to evaluate OPTRAM's accuracy. The reference CRN soil moisture exhibits an area of influence similar to the size of a MODIS pixel. This similarity helps to reduce uncertainties in the comparisons. The CDF matching method was applied to eliminate bias (timeinvariant errors) and to rescale OPTRAM and microwave-based soil moisture estimates. Longterm MODIS data (since 2001) was used to map long-term soil moisture dynamics with OPTRAM and to track environmental changes. For example, a soil water deficit index (OPTRAM-SWDI) was calculated based on OPTRAM soil moisture estimates and a soil water availability concept to explore the potential of OPTRAM-MODIS to monitor agricultural drought. The OPTRAM-SWDI was compared with an atmospheric drought index (CMI) to identify and capture drought dynamics over diverse climates, soil types and land covers.

Matching the CDFs significantly decreased the estimation errors (bias, RMSE, ubRMSE), while having no impact on $R$ values. It was found that the original OPTRAM and microwave soil moisture estimates were highly correlated with CRN soil moisture at each site. OPTRAM successfully captured the temporal dynamics of the SMAP, SMOS, and ASCAT soil moisture retrievals for all sites. OPTRAM performed well for all test sites with ubRMSE ranging between 0.0501 and $0.0853 \mathrm{~cm}^{3} \mathrm{~cm}^{-3}$ and $R$ ranging between 0.10 and 0.70 . The SMAP and SMOS retrievals were more accurate than the OPTRAM estimates for all CRN sites, verifying higher sensitivity of passive microwaves to soil moisture than optical reflectance observations. The OPTRAM, however, performed similar to or slightly better than the ASCAT sensor.

A universal parameterization of OPTRAM can be obtained for a given region based on long-term MODIS data. In this study we used a visual inspection approach for determining the dry and wet edges. The results indicate that OPTRAM is not significantly confined to visual fitting of 
the dry and wet edges. Future studies are underway to derive physically-based fitting model to better determine the dry and wet edges.

Due to moderate spatial and high temporal resolution of MODIS images, OPTRAM estimates could be helpful for monitoring soil moisture for agricultural fields and the STR-NDVI space could be used for downscaling of microwave satellite soil moisture products.

A similar pattern was observed between OPTRAM-SWDI and CMI at most sites. The drought events were clearly captured by OPTRAM-SWDI. These results demonstrate that the OPTRAM-SWDI is able to adequatly capture drought dynamics for a wide range of climate, soil type and land cover conditions, portending OPTRAM's feasibility as a tool for agricultural drought monitoring. The calculation of SWDI is based on soil water retention parameters such as the field capacity and permanent wilting point. The international soil datasets such as the Harmonized World Soil Database (FAO/ISRIC/ISSCAS/JRC, 2012) in conjuction with a pedotransfer function approach can provide good estimates of soil water retention parameters. Thus, where soil property databases are available, SWDI can be estimated from the OPTRAM.

\section{Acknowledgments}

The authors gratefully acknowledge funding from the National Science Foundation (NSF) grant no. 1521469 and acknowledge use of data from the COsmic-ray Soil Moisture Observing System (COSMOS), funded by the US National Science Foundation (ATM-0838491).

\section{References}

Akbar, R., Moghaddam, M., 2015. A combined active passive soil moisture estimation algorithm with adaptive regularization in support of SMAP. IEEE Transactions on Geoscience and Remote Sensing. 53(6), 3312-3324. 
Albergel, C., Rudiger, C., Pellarin, T., Calvet, J. C., Fritz, N., Froissard, F., Martin, E., 2008. From near-surface to root-zone soil moisture using an exponential filter: An assessment of the method based on in-situ observations and model simulations. Hydrology and Earth System Sciences. 12, 1323-1337.

Al-Yaari, A., Wigneron, J.-P., Ducharne, A., Keer, Y.H., Wagner, W., De Lannoy, G., Reichle, R., Al Bitar, A., Dorigo, W., Richaume, P., Mialon, A., 2014. Global scale comparison of passive (SMOS) and active (ASCAT) satellite based microwave soil moisture retrievals with soil moisture simulations (MERRA-Land). Remote Sensing of Environment. 152, 614-626.

Andreasen, M., Jensen, K.H., Desilets, D., Franz, T.E., Zreda, M., Bogena, H.R., Looms, M.C., 2017. Status and perspectives on the cosmic-ray neutron method for soil moisture estimation and other environmental science applications. Journal of Hydrology. 16(8).

Avery, W.A., Finkenbiner, C., Franz, T.E., Wang, T., Nguy-Robertson, A.L., Suyker, A., Arkebauer, T., Arriola, F.M., 2016. Incorporation of globally available datasets into the roving cosmic-ray neutron probe method for estimating field-scale soil water content. Hydrological Earth System Science. 20, 3859-3872.

Baatz, R., Bogena, H.R., Franssen, H.-J.H., Huisman, J.A., Montzka, C., Vereecken, H., 2015. An empirical vegetation correction for soil moisture content quantification using cosmic ray probes. Water Resources Research. 51, 2030-2046.

Babaeian, E., Homaee, M., Montzka, C., Vereecken, H., Norouzi, A.A. and van Genuchten, M.T., 2016. Soil moisture prediction of bare soil profiles using diffuse spectral reflectance information and vadose zone flow modeling. Remote Sensing of Environment. 187, 218-229.

Bartalis, Z., Wagner, W., Naeimi, V., Hasenauer, S., Scipal, K., Bonekamp, H., Figa, J., Anderson, C., 2007. Initial soil moisture retrieval from the METOP-A Advanced Scatterometer (ASCAT). Geographical Research Letters. 34, L20401.

Bogena, H.R., Huisman, J.A., Baatz, R., Franssen, H.-J.H., Vereecken, H., 2013. Accuracy of the cosmic-ray soil water content probe in humid forest ecosystems: The worst case scenario. Water Resources Research. 49, 5778-5791.

Brocca, L., Hasenauer, S., Lacava, T., Melone, F., Moramacrco, T., Wagner, W., Dorigo, W., Matgen, P., Martinez-Fernandez, J., Llorens, P., Latron, J., Martin, C., Bittelli, M., 2011. Soil moisture estimation through ASCAT and AMSR-E sensors: An intercomparison and validation study across Europe. Remote Sensing of Environment. 115, 3390-3408.

Cammalleri, C., Micale, F., Vogt, J., 2016. A novel soil moisture-based drought severity index (DSI) combining water deficit magnitude and frequency. Hydrological Processes. 30(2), 289301.

Carlson, T.N., 2013. Triangle models and misconceptions. International Journal Remote Sensing Applications. 3 (3), 155-158.

Carlson, T.N., Gillies, R.R., Perry, E.M., 1994. A methoCd to make use of thermal infrared temperature and NDVI measurements to infer surface soil water content and fractional vegetation cover. Remote Sensing Reviews. 9(1-2), 161-173. 
Carrao, H., Russo, S., Sepulcre-Canto, G., Barbosa, P., 2016. An empirical standardized soil moisture index for agricultural drought assessment from remotely sensed data. International Journal of Applied Earth Observation and Geoinformation. 48, 74-84.

Chakrabarti, S., Bongiovanni, T., Judge, J., Zotarelli, L., Bayer, C., 2014. Assimilation of SMOS soil moisture for quantifying drought impacts on crop yield in agricultural regions. IEEE Journal of Selected Topics in Applied Earth Observations and Remote Sensing. 7(9), 38673879.

Chapin, E., Chau, A., Chen, J., Heavey, B., Hensley, S., Lou, Y., Machuzak, R. and Moghaddam, M., 2012. AirMOSS: An airborne P-band SAR to measure root-zone soil moisture. Proc. IEEE Radar Conference. Atlanta, GA, 693-698.

Crow, W., Koster, R., Reichle, R., Sharif, H.,2005. Relevance of time-varying and time-invariant retrieval error sources on the utility of spaceborne soil moisture products. Geophysical Research Letters. 32, L24405. doi: 10.1029/2005GL024889.

Desilets, D., Zreda, M., 2013. Footprint diameter for a cosmic-ray soil moisture probe: Theory and Monte Carlo simulations. Water Resources Research. doi:10.1002/wrcr.20187.

Djamai, N., Magagi, R., Goita, K., Hosseini, M., Cosh, M.H., Berg, A., Toth, B., 2015. Evaluation of SMOS soil moisture products over the CanEx-SM10 area. Journal of Hydrology. 520, 254267.

Entekhabi, D., Njoku, E.G., O'Neill, P.E., Kellogg, K.H., Crow, W.T., Edelstein, W.N., Entin, J.K., Goodman, S.D., Jackson, T.J., Johnson, J. and Kimball, J., 2010. The soil moisture active passive (SMAP) mission. Proceedings of the IEEE. 98(5), 704-716.

Escorihuela, M.J., Chanzy, A., Wigneron, J.P., Kerr, Y.H., 2010. Effective soil moisture sampling depth of L-band radiometry: A case study. Remote Sensing of Environment. 114, 995-1001.

Evans, J.G., Ward, H.C., Blake, J.R., Hewitt, E.J., Morrison, R., Fry, M., et al., 2016. Soil water content in southern England derived from a cosmic-ray soil moisture observing system: COSMOS-UK. Hydrological Processes. 30, 4987-4999.

Fascetti, F., Pierdicca, N., Pulvirenti, L., Crapolicchio, R., Munoz-Sabater, J., 2016. A comparison of ASCAT and SMOS soil moisture retrievals over Europe and Northern Africa from 2010 to 2013. International Journal of Applied Earth Observation and Geoformation. 45, 135-142.

Fernandez-Moran, R., Al-Yaari, A., Mialon, A., Mahmoodi, A., Al Bitar, A., De Lannoy, G., Rodriguez-Fernandez, N., Lopez-Baeza, E., Kerr, Y., Wigneron, J.P. 2017. SMOS-IC: An alternative SMOS soil moisture and vegetation optical depth product. Remote Sensing. 9, 457.

Franz, T.E., Zreda, M., Rosolem, R., Ferré, T.P.A., 2013. A universal calibration function for determination of soil moisture with cosmic-ray neutrons. Hydrological Earth System Science. 17, 453-460.

Franz, T.E., Zreda, M., Rosolem, R., Ferre, T.P.A., 2012. Field validation of a cosmic-ray neutron sensor using a distributed sensor network. Vadose Zone Journal. 11(4).

Gillies, R.R., Carlson, T.N., 1995. Thermal Remote Sensing of Surface Soil Water Content with Partial Vegetation Cover for Incorporation into Climate Models. Journal of Applied Meteorology. 34, 745-756. 
Hallikainen, M.T., Ulaby, F.T., Dobson, M.C., El-Rayes, M.A., 1985. Microwave dielectric behaviorofwetsoil-part1: empirical models and experimental observations. IEEE Transactions on Geoscience and Remote Sensing. 23(1), 25-34.

Hawdon, A., McJannet, D., Wallace, J., 2014. Calibration and correction procedures for cosmicray neutron soil moisture probes located across Australia. Water Resources Research. 50, 5029-5043.

Hirschi, M., Mueller, B., Dorigo, W., Seneviratne, S. I., 2014. Using remotely sensed soil moisture for land-atmosphere coupling diagnostics: The role of surface vs. root-zone soil moisture variability. Remote SensIng of Environment. 154, 246-252.

Hogg, E.H., Hurdle, P.A., 1995. The aspen parkland in western Canada: a dry-climate analogue for the future boreal forest? Water, Air, and Soil Pollution. 82, 391-400.

Huete, A., 1988. A soil adjusted vegetation index (SAVI). Remote Sensing of Environment. 25 (3), 295-309. doi:10.1016/0034-4257(88)90106-X.

Kabat, P., Beekma, J., 1994. Water in the unsaturated zone. In: Ritzema, H.P. (Ed.), Drainage Principles and Applications. ILRI Publication 16, second ed. International Institute for Land Reclamation and Improvement, Wageningen, the Netherlands. 383-434.

Keefer, T.O., Moran, M.S. Paige, G.B., 2008. Long-term meteorological and soil hydrology database, Walnut Gulch Experimental Watershed, Arizona, United States. Water Resources Research. 44(5), W05S07.

Kerr, H., Waldteufel, P., Wigneron, J.P., Martinuzzi, J., Font, J., Berger, M., 2001. Soil moisture retrieval from space: The Soil Moisture and Ocean Salinity (SMOS) mission. IEEE Transactions on Geoscience and Remote Sensing. 39, 1729-1735.

Kerr, Y.H., Waldteufel, P., Richaume, P., Wigneron, J.P., Ferrazzoli, P., Mahmoodi, A., Al Bitar, A., Cabot, F., Gruhier, C., Juglea, S.E., et al., 2012. The SMOS soil moisture retrieval algorithm. IEEE Transactions on Geoscience and Remote Sensing. 50, 1384-1403.

Kohli, M., Schron, M., Zreda, M., Schmidt, U., Dietrich, P., Zacharias, S., 2015. Footprint characteristics revised for field-scale soil moisture monitoring with cosmic-ray neutrons. Water Resources Research. 51(7), 5772-5790.

Koster, R.D., Guo, Z., Yang, R., Dirmeyer, P.A., Mitchell, K., Puma, M., 2009. On the nature of soil moisture in land surface models. Journal of Climate. 22, 4322-4335.

Kumar, S.V., Reichle, R.H., Harrison, K.W., Peters-Lidard, C.D., Yatheendradas, S., Santanello, J.A., 2012. A comparison of methods for a priori bias correction in soil moisture data assimilation. Water Resources Research. 48, W03515.

Liu, D., Mishra, A.K., Yu, Z.B., Yang, C.G., Konapala, G., Vu, T., 2017. Performance of SMAP, AMSR-E and LAI for weekly agricultural drought forecasting over continental United States. Journal of hydrology. 555, 88-104.

Liu, H.Q., Huete, A., 1995. A feedback based modification of the NDVI to minimize canopy background and atmospheric noise. IEEE Transactions on Geoscience and Remote Sensing. 33 (2), 457-465. 
Lv, L., Franz, T.E., Robinson, D.A., Jones, S.B., 2014. Measured and Modeled Soil Moisture Compared with Cosmic-Ray Neutron Probe Estimates in a Mixed Forest. Vadose Zone Journal. 13(12). doi:10.2136/vzj2014.06.0077

Martinez-Fernandez, J., Gonzalez-Zamora, A., Sanchez, N., Gumuzzio, A., 2015. A soil water based index as a suitable agricultural drought indicator. Journal of Hydrology. 522, 265-273.

Martinez-Fernandez, J., Gonzalez-Zamora, A., Sanchez, N., Gumuzzio, A., Herrero-Jimenez, C.M., 2016. Satellite soil moisture for agricultural drought monitoring: Assessment of the SMOS derived Soil Water Deficit Index. Remote Sensing of Environment. 177, 277-286.

Mattikalli, N.M., Engman, E.T, Jackson, T.J., Ahuja, L.R., 1998. Microwave remote sensing of temporal variations of brightness temperature and near surface soil water content during a watershed-scale field experiment, and its application to the estimation of soil physical properties. Water Resources Research. 34, 2289-2299.

McKee, T.B., Doesken, N.J., Kleist, J., 1993.The Relationship of Drought Frequency and Duration to Time Scales. Proceedings of the Eighth Conference on Applied Climatology. American Meteorological Society: Boston; 179-184.

McPherson, R.A., Fiebrich, C.A., Crawford, K.C., Kilby, J.R., Grimsley, D.L., Martinez, J.E., Basara, J.B., Illston, B.G., Morris, D.A., Kloesel, K.A. and Melvin, A.D., 2007. Statewide monitoring of the mesoscale environment: A technical update on the Oklahoma Mesonet. Journal of Atmospheric Oceanic Technology. 24(3), 301-321.

Merlin, O., Rüdiger, C., Al Bitar, A., Richaume, P., Walker, J. Kerr, Y., 2012. Disaggregation of SMOS soil moisture in southeastern Australia. IEEE Transactions on Geoscience and Remote Sensing. 99, 1-16.

Mironov, V.L., Kosolapova, L.G., Fomin, S.V., 2009. Physically and mineralogically based spectroscopic dielectric model for moist soils. IEEE Transactions on Geoscience and Remote Sensing. 47, 2059-2070.

Mishra, A., Vu, T., Veetti, A.V., Entekhabi, D., 2017. Drought Monitoring with Soil Moisture Active Passive (SMAP) Measurements. Journal of Hydrology. 552.

Montzka, C., Bogena, H.R, Zreda, M., Monerris, A., Morrison, R., Muddu, S., Verrecken, H., 2017. Validation of spaceborne and modelled surface soil moisture products with cosmic-ray neutron probes. Remote Sensing. 9, 103.

Nachtergaele, F.O., van Velthuizen, H.T., Verelst, L., Wiberg, D., Batjes, N.H., Dijkshoorn, J.A., van Engelen, V.W.P., Fischer, G., Jones, A., Montanarella, L., et al., 2012. Harmonized World Soil Data base (Version 1.2), FAO, Rome, Italy, IIASA, Laxenburg, Austria.

Naeimi, V., Scipal, K., Bartalis, Z., Hasenauer, S., Wagner, W., 2009. An improved soil moisture retrieval algorithm for ERS and METOP scatterometer observations. IEEE Transactions on Geoscience and Remote Sensing. 47, 1999-2013.

Owen, T.W., Carlson, T.N., Gillies, R.R., 1998. An Assessment of satellite remotely-sensed Land Cover Parameters in Quantitatively Describing the Climatic Effect of Urbanization. International Journal of Remote Sensing. 19, 1663-1681.Palmer, W. C., 1965. Meteorological drought. U.S. Weather Research Paper 45. Washington D.C.: U.S. Weather Bureau. 
Palmer, W. C., 1968. Keeping track of crop moisture conditions, nationwide: The new crop moisture index. Weatherwise. 21(4), 156-161

Peng, J., Niesel, J., Loew, A., Zhang, S., Wang, J., 2015. Evaluation of Satellite and Reanalysis Soil Moisture Products over Southwest China Using Ground-Based Measurements. Remote Sensing. 7, 15729-15747.

Piles, M., Sánchez, N., Vall-llossera, M., Camps, A., Martínez-Fernández, J., Martinez, J. and Gonzalez-Gambau, V., 2014. A downscaling approach for SMOS land observations: Evaluation of high-resolution soil moisture maps over the Iberian Peninsula. IEEE Journal of Selected Topics in Applied Earth Observations and Remote Sensing. 7(9), 3845-3857.

Rahimzadeh-Bajgiran, P., Berg, A.A., Champagne, C. and Omasa, K., 2013. Estimation of soil moisture using optical/thermal infrared remote sensing in the Canadian Prairies. ISPRS Journal of Photogrammetry and Remote Sensing. 83, 94-103.

Reichle, R. H., Koster, R.D., 2004. Bias reduction in short records of satellite soil moisture. Geographical Research Letters. 31, L19501.

Renard, K.G., Lane, L.J., Simanton, J.R., Emmerich, W.E., Stone, J.J., Weltz, M.A., Goodrich, D.C. and Yakowitz, D.S., 1993. Agricultural impacts in an arid environment: Walnut Gulch studies. Hydrological Science and Technology. 9(1-4), 145-190.

Rim, C.S., 2000. A comparison of approaches for evapotranspiration estimation. KSCE Journal of Civil Engineering. 4(1), 47-52.

Robinson, D.A., Campbell, C.S., Hopmans, J.W., Hornbuckle, B.K., Jones, S.B., Knight, R., Ogden, F., Selker, J., Wendroth, O., 2008. Soil moisture measurement for ecological and hydrological watershed-scale observatories: A Review. Vadose Zone Journal. 7(1), 358-389. doi:10.2136/vzj2007.0143.

Rosolem, R., Shuttleworth, W.J., Zreda, M., Franz, T.E., Zeng, X., Kurc, S.A., 2013. The effect of atmospheric water vapor on neutron count in the cosmic-ray soil moisture observing system. Journal of Hydrometeorology. 14, 1659-1671.

Shafian, S., Maas, S.J., 2015. Improvement of the Trapezoid method using raw Landsat image digital count data for soil moisture estimation in the Texas (USA) High Plains. Sensors. 15(1), 1925-1944.

Sadeghi, M., Babaeian, E., Tuller, M., Jones, S.B., 2017. The optical trapezoid model: a novel approach to remote sensing of soil moisture applied to Sentinel-2 and Landsat-8 observations. Remote Sensing of Environment. 198, 52-68.

Sadeghi, M., Jones, S.B., Philpot, W.D., 2015. A linear physically-based model for remote sensing of soil moisture using short wave infrared bands. Remote Sensing of Environment. 164, 6676.

Santos, W.J.R., Silva, B.M., Oliveira, G.C., Volpato, M.M.L., Lima, J.M., Curi, N., Marques, J.J., 2014. Soil moisture in the root zone and its relation to plant vigor assessed by remote sensing at management scale. Geoderma. 221, 91-95.

Schaap, M.G., Leij, F.J., van Genuchten, M.T., 2001. ROSETTA: a computer program for estimating soil hydraulic parameters with hierarchical pedotransfer functions. Journal of Hydrology. 251(3-4), 163-176. 
Sohrabi, M.M., Ryu, J.H., Abatzoglou, J., Tracy, J., 2015. Development of soil moisture drought index to characterize droughts. Journal of Hydrologic Engineering. 20(11), 04015025.

Sridhar, V., Hubbard, K.G., You, J., Hunt, E.D., 2008. Development of the soil moisture index to quantify agricultural drought and its "user friendliness" in severity-area-duration assessment. Journal of Hydrometeorology. 9(4), 660-676.

Sun, H., 2016. Two-Stage Trapezoid: A New Interpretation of the Land Surface Temperature and Fractional Vegetation Coverage Space. IEEE Journal of Selected Topics in Applied Earth Observations and Remote Sensing. 9(1), 336-346.

Tabatabaeenejad, A., Burgin, M., Duan, X., Moghaddam, M., 2015. P-band radar retrieval of subsurface soil moisture profile as a second-order polynomial: First AirMOSS results. IEEE Transactions on Geoscience and Remote Sensing. 53(2), 645-658.

Thornthwaite, C.W., 1948. An approach towards a rational classification of climate. Geographical Review. 38, 55-94.

Torres-Ruiz, J.M., Diaz-Espejo, A., Morales-Sillero, A., Martín-Palomo, M. J., Mayr, S., Beikircher, B., Fernández, J.E., 2013. Shoot hydraulic characteristics, plant water status and stomatal response in olive trees under different soil water conditions. Plant and Soil. 373(1-2), 77-87.

U.S. Geological Survey, 1986. Hydrologic events and surface-water resources in National Water Summary: U.S. Geological Survey Water-Supply Paper 2300.

Van der Schalie, R., Kerr, Y. H., Wigneron, J. P., Rodríguez-Fernández, N. J., Al-Yaari, A., de Jeu, R.A.M., 2016. Global SMOS soil moisture retrievals from the land parameter retrieval model. International Journal of Applied Earth Observation and Geoinformation. 45, 125-134.

van Genuchten, M. Th., 1980. A closed-form equation for predicting the hydraulic conductivity of unsaturated soils. Soil Science Society of America Journal. 44, 892-898.

Vereecken, H., Huisman, J.A., Pachepsky, Y., Montzka, C., van der Kruk, J., Bogena, H., Weihermüller, L., Herbst, M., Martinez, G., Vanderborght, J., 2014. On the spatio-temporal dynamics of soil moisture at the field scale. Journal of Hydrology. 516, 76-96.

Wagner, W., Hahn, S., Kidd, R., Melzer, T., Bartalis, Z., Hasenauer, S., Figa-Saldana, J., de Rosnay, P., Jann, A., Schneider, S., Komma, J., 2013. The ASCAT soil moisture product: a review of its specifications, validation results and emerging applications. Meteorologische Zeitschrift. 22, 5-23.

Wigneron, J.P., Kerr, Y., Waldteufel, P., Saleh, K., Escorihuela, M.J., Richaume, P., Ferrazzoli, P., de Rosnay, P., Gurney, R., Calvet, J.C., et al., 2007. L-band microwave emission of the biosphere (L-MEB) model: Description and calibration against experimental data sets over crop fields. Remote Sensing of Environment. 107, 639-655.

Zhang, F., Zhang, L., Wang, X., Hung, J., 2013. Detecting agro-droughts in Southwest of China using MODIS satellite data. Journal of Integrative Agriculture. 12 (1), 159-168.

Zreda, M., Shuttleworth, W.J., Zeng, X., Zweck, C., Desilets, D., Franz, T., Rosolem, R., 2012. COSMOS: the Cosmic-ray Soil Moisture Observation System. Hydrological Earth System Science. 16, 4079-4099. 
Zreda, M., Desilets, D., Ferre, T.P.A., Scott, R.L., 2008. Measuring soil moisture content noninvasively at intermediate spatial scale using cosmic-ray neutrons. Geographical Research Letters. 35, L21402. 